\title{
Contributions of Different Combinations of the IPO and AMO to the Concurrent Variations of Summer East Asian Jets
}

\author{
Xiucheng Xiao, Danqing Huang, and Ben Yang \\ School of Atmospheric Sciences, Nanjing University, Nanjing, China \\ JIAN ZHU \\ College of Hydrology and Water Resources, Hohai University, Nanjing, China \\ PEIWEN YAN \\ Meteorological Bureau of Shaoxing, Shaoxing, China \\ YAOCUN ZHANG \\ School of Atmospheric Sciences, Nanjing University, Nanjing, China
}

(Manuscript received 20 May 2019, in final form 9 June 2020)

\begin{abstract}
Huang et al. recently reported that opposite phases of the interdecadal Pacific oscillation (IPO) and the Atlantic multidecadal oscillation (AMO) can affect the shift of the East Asian polar front jet (EAPJ) and the East Asian subtropical jet (EASJ) in the boreal winter. To give a full image of the relationship among the IPO, AMO, and concurrent variation of jets throughout the whole year, this study investigates the changes in summer jets response to the combinations of the IPO and AMO, and mostly focuses on the quantitative analysis in the role of the IPO and AMO. Both of the diagnostic analysis and atmospheric model simulations confirm that combinations of the negative phase of the IPO ("-IPO") and the positive phase of the AMO ("+AMO") can significantly enhance the EAPJ and reduce the EASJ in the summer, via the meridional temperature gradient and the Eady growth rate, and vice versa in the "+ IPO - AMO" combination. The reanalysis data show that this relationship is particularly evident between the periods of 1999-2014 and 1979-98. Based on the simulations, the multilinear regression has indicated that -IPO plays a more important role than +AMO, particularly for the reduced EASJ. We have further revealed two pathways of the stationary Rossby wave activity anomaly, eastward from the North Atlantic to East Asia along $60^{\circ} \mathrm{N}$ and westward from the North Pacific to East Asia along $40^{\circ} \mathrm{N}$. The two activities are associated with anomalous anticyclone along the active regions between EAPJ and EASJ, and therefore affect the jet variations.
\end{abstract}

\section{Introduction}

In the upper troposphere, two westerly jet stream branches locate over East Asia throughout the whole year, the East Asian polar front jet (EAPJ) and the East Asian subtropical jet (EASJ). In the boreal summer, both the EAPJ and EASJ play important roles in the changes of atmospheric circulation (Kug et al. 2010), temperature, and precipitation over East Asia (Huang et al. 2014; Li and Zhang 2014; Yan and Huang 2017;

\footnotetext{
Corresponding author: Dr. Danqing Huang, huangdq@nju.edu.cn
}

Sampe and Xie 2010; Horinouchi and Hayashi 2017), although the two jets are weaker in summer than in winter (e.g., Zhang et al. 2008; Luo and Zhang 2015; Xue and Zhang 2017; Huang et al. 2017). Therefore, analyzing changes in the summer jets is helpful to understand the climate variations over East Asia.

Recently, the concurrent variation of the two jets have been emphasized rather than the variation of individual jets, since the former reflects the compound variations in the low- and high-latitude circulations over East Asia (Liao and Zhang 2013; Huang et al. 2014; Li and Zhang 2014; Huang et al. 2015; Zhu et al. 
2016a; Luo and Zhang 2015; Huang et al. 2017). For example, the different configurations of the EAPJ and EASJ affect the local circulations and water vapor flux, and therefore result in a dipole pattern of the summer precipitation over East China (Huang et al. 2014). The composite of enhanced EAPJ and reduced EASJ results in a "southern flood-northern drought" rainfall pattern over eastern China in summer, by affecting the cold and warm air activity (Zhu et al. 2016a). The different patterns of mei-yu, the unique phenomenon over YangtzeHuaihe River basin (Qian et al. 2007; Huang et al. 2011; Zhu et al. 2013, 2016b), are also found to be associated with the different configurations of the EAPJ and EASJ at the interannual ( $\mathrm{Li}$ and Zhang 2014) and subseasonal scale (Yan and Huang 2017). Some thermal factors would affect the variation of the two jets (Lu et al. 2013), such as the tropical oceanic convective activities ( $\mathrm{Lu}$ 2005; Lin and Lu 2009), the East Asia-Pacific teleconnection wave train (Tsuyuki and Kurihara 1989; Huang and Sun 1992; Lu and Lin 2009; Qu and Huang 2012), the meridional temperature gradient (MTG) (Seidel et al. 2008; Si et al. 2009; Yim et al. 2015), and the baroclinic activities (Ren et al. 2010; Huang et al. 2019; Zhang et al. 2019). Particularly, the sea surface temperature (SST) variation over the Pacific and Atlantic Ocean (Zhang et al. 1996; Dong et al. 1999; Wang et al. 2000; Lin and Lu 2009; He et al. 2016).

For the decadal scale, the two dominant modes for decadal SST variations are the interdecadal Pacific oscillation [IPO; Power et al. 1999; Dai 2013; Dong and Dai 2015; also referred as the Pacific decadal oscillation (PDO)] and the Atlantic multidecadal oscillation [AMO; Enfield et al. 2001; Trenberth and Shea 2006; also referred as the Atlantic multidecadal variability (AMV); Liu 2012]. Previous studies have analyzed the impact of the AMO and IPO on the precipitation and temperature, separately. The IPO has impacted on the variation of the surface air temperature and precipitation over Australia and the U.S. Southwest (Dong and Dai 2015). The IPO transition from negative to positive phase impacted the decline and recovery in the Indian summer monsoon before and after 1999 (Huang et al. 2020). For East Asia, the warm phase of the PDO would weaken the East Asian summer monsoon (Zhu and Yang 2003), while the AMO would intensify the East Asian summer monsoon (Li et al. 2009). The influence of the AMO on the frequency of the summer drought in eastern China has been increasing over the past decade, particularly after the 1990s (Qian et al. 2014).

In fact, on the one hand, the combinations of the IPO and AMO have greater impacts on temperature and precipitation variations than each has individually. Joshi and Rai (2015) revealed that the opposite phases of the AMO and IPO together influenced both of the total and moderate rainfall over west central and northeast Indian peninsula. The concurrent variations of the IPO and AMO are associated with a quaternary summer precipitation anomaly pattern over East Asia (Zhang et al. 2018). The interdecadal seesaw of precipitation variability between North China and the U.S. Southwest is modulated by the concurrent variations of IPO and AMO (Yang et al. 2019). However, their impacts on atmospheric circulations have received little attention, especially for East Asia. On the other hand, it has been noticed that both the summer EAPJ and EASJ have experienced significant changes in the mid-1990s (e.g., Kwon et al. 2007; Lu et al. 2011, 2013; Zhang and Huang 2011), with a significant decrease (increase) in the strength of zonal wind near the active region of the EASJ (EAPJ) after the mid-1990s. At the interannual scale, the intensity of the EASJ has significantly weakened (Lu et al. 2011, 2013). Thus, the linkage between the combinations of the IPO and AMO and the concurrent variations of the EAPJ and EASJ in the summer is still unclear.

In 2019 we showed that the concurrent variation of winter EAPJ and EASJ is accompanied by the opposite phases of the IPO and AMO, via the thermal impacts and dynamic energy conversions (Huang et al. 2019). However, in our former study, the relative contributions of the IPO and AMO had not been quantitatively distinguished. Moreover, the SST variations over the Atlantic and Pacific Ocean may not directly affect the East Asian climate. Thus, the longdistance impact pathways need to be investigated. In all, focusing on the boreal summer, this study answers the following questions: 1) How do the combinations of IPO and AMO affect the summer EAPJ and EASJ? 2) What are the possible mechanisms? 3) What are the relative contributions and impact pathways? The rest of paper is arranged as follows. Section 2 describes the data and methods. Section 3 examines the linkage between different combinations of the IPO and AMO and the jet variations. In section 4, based on both of the diagnostic analyses and numerical experiments, a possible mechanism for the changes in the two jets between the groups of negative IPO and positive ("-IPO + AMO"; mostly in 1999-2014) and of positive IPO and negative AMO ("+ IPO - AMO"; mostly in 197998) has been proposed. The quantitative contributions of the IPO and AMO have been further explored by the model simulations in section 5. The results are summarized in section 6 , together with a discussion of this study and of Huang et al. (2019). 

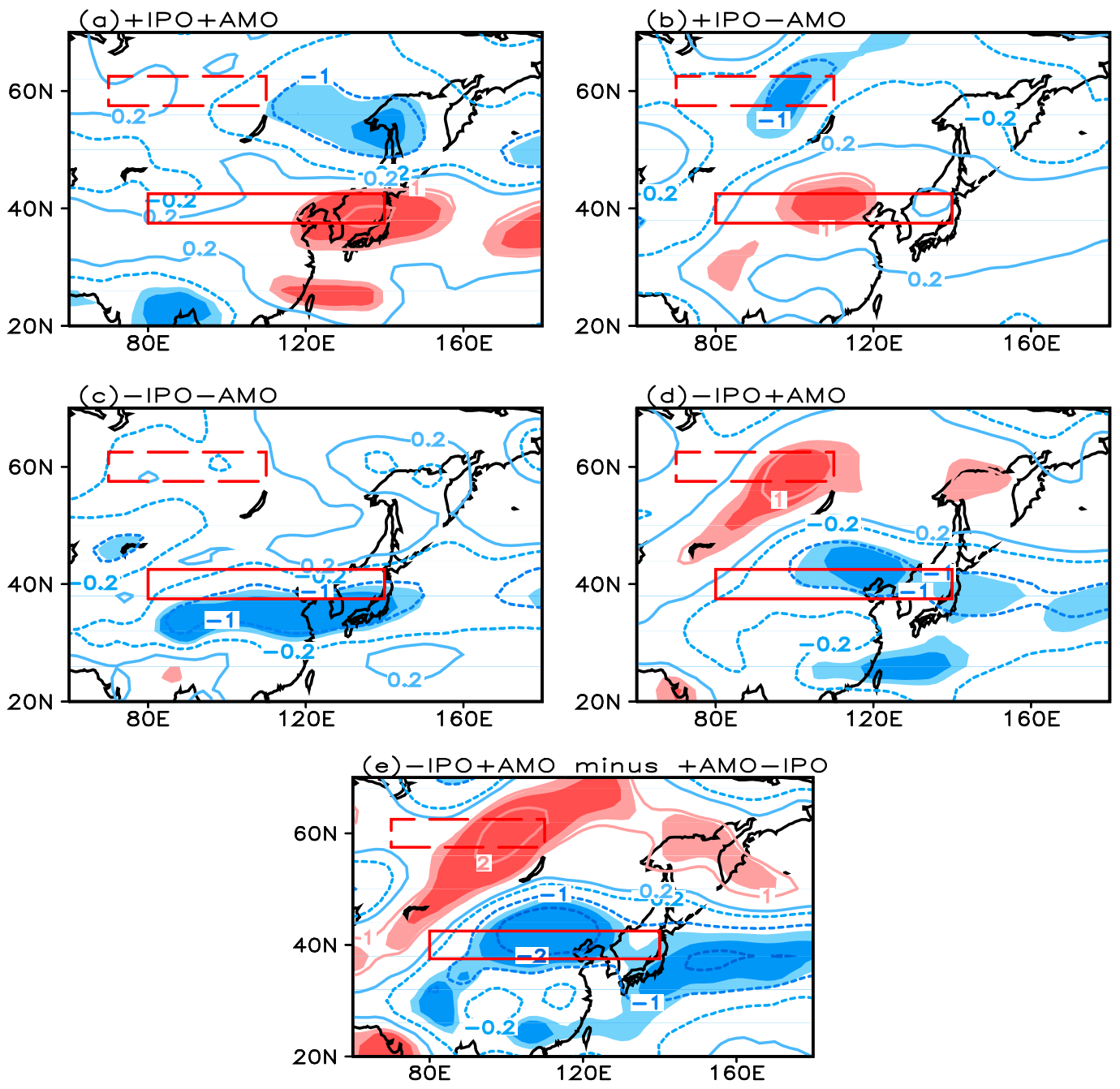

FIG. 1. The 300-hPa JJA composite mean wind speed anomalies relative to the 1920-2014 mean (unit: $\mathrm{m} \mathrm{s}^{-1}$ ) for the (a) + IPO + AMO, (b) + IPO - AMO, (c) - IPO - AMO, and (d) - IPO + AMO groups, and (e) the differences between the $-\mathrm{IPO}+\mathrm{AMO}$ and + IPO - AMO groups (unit: $\mathrm{m} \mathrm{s}^{-1}$ ) based on the 20CR reanalysis datasets. The red dashed (solid) box indicates the active region of the EAPJ, $57.5^{\circ}-62.5^{\circ} \mathrm{N}, 70^{\circ}-110^{\circ} \mathrm{E}\left(\mathrm{EASJ} ; 37.5^{\circ}-42.5^{\circ} \mathrm{N}, 80^{\circ}-140^{\circ} \mathrm{E}\right)$. The light (dark) shadings indicate that the difference is significant at the $90 \%$ (95\%) level based on Student's $t$ test. Notice that the IPO and AMO indices are derived as the PC of the second leading EOF of 3-yr-moving-average annual SSTs in near-global $\left(60^{\circ} \mathrm{S}-60^{\circ} \mathrm{N}\right)$ oceans (for the IPO) and PC1 of the EOF1 of the detrended annual SST over the North Atlantic $\left(20^{\circ}-70^{\circ} \mathrm{N}, 70^{\circ} \mathrm{W}-0^{\circ}\right.$; for the AMO).

\section{Data and methods}

The data, methods, and figure formats closely follow Huang et al. (2019) but are applied to the boreal summer season (June-August).

\section{a. Data}

Four reanalysis datasets are used: 1 ) the Twentieth Century Reanalysis version 2 from 1920 to 2014 on a $2^{\circ} \times 2^{\circ}$ grid (20CR; Compo et al. 2011); 2) the ECMWF interim reanalysis from 1979 to 2014 on a $1^{\circ} \times 1^{\circ}$ grid (ERA-Interim; Dee et al. 2011); 3) the Modern-Era Retrospective Analysis for
Research and Applications from 1979 to 2014 on a $\sim 0.67^{\circ} \times$ $0.5^{\circ}$ grid (MERRA; Gelaro et al. 2017); and 4) the National Centers for Environmental Prediction-National Center for Atmospheric Research reanalysis from 1979 to 2014 on a $2.5^{\circ} \times 2.5^{\circ}$ grid (NCEP-NCAR; Kalnay et al. 1996).

\section{b. Model experiments}

As in Huang et al. (2019), using the Community Earth System Model (CESM1.2.0) with the Community Atmosphere Model (CAM5) physics (Neale et al. 2012), the CTRL run and five sensitivity experiments (EXP_All, 

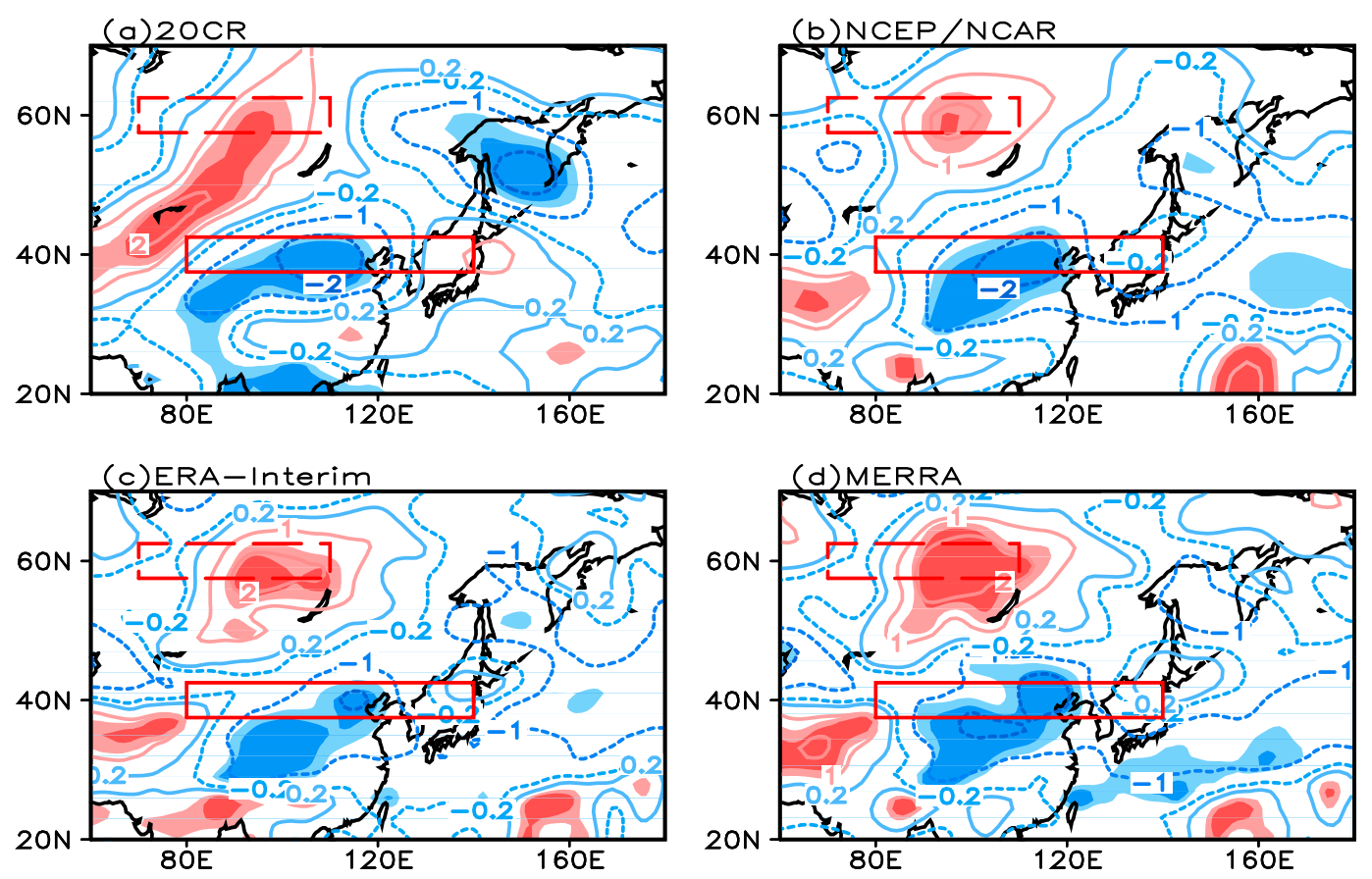

FIG. 2. The 300-hPa JJA wind speed differences between 1999-2014 and 1979-98 (unit: $\mathrm{m} \mathrm{s}^{-1}$ ) from the (a) 20CR, (b) NCEP-NCAR, (c) ERA-Interim, and (d) MERRA reanalysis datasets. The red dashed (solid) box indicates the active region of the EAPJ (EASJ). The light (dark) shadings indicate that the difference is significant at the $90 \%(95 \%)$ level based on Student's $t$ test.

EXP_A, EXP_P, EXP_AP, and EXP_IP) are used in this study. Detailed descriptions about the model experimental configurations are provided in Huang et al. (2019).

\section{c. Methods}

Based on several indices of the IPO (Dai 2013; Joshi and Kucharski 2017; National Oceanic and Atmospheric Administration Earth System Research Laboratory, available from https://www.esrl.noaa.gov/psd/data/timeseries/IPOTPI/) and the AMO (Enfield et al. 2001; Trenberth and Shea 2006; Sutton and Dong 2012), four groups in the IPO and AMO combinations have been distinguished (Huang et al. 2019). Following Huang et al. (2019), we also used the composite analysis to examine the atmospheric circulation anomalies (relative to 1920-2014 mean) for each group by averaging over all the years within the group.

Following the selection standards in Huang et al. (2014) and $\mathrm{Li}$ and Zhang (2014), the regions of 57.5 $62.5^{\circ} \mathrm{N}, 70^{\circ}-110^{\circ} \mathrm{E}$ and of $37.5^{\circ}-42.5^{\circ} \mathrm{N}, 80^{\circ}-140^{\circ} \mathrm{E}$ are chosen as the active region of the summer EAPJ and EASJ, respectively. The intensity indices of the two jets are defined as the regional-mean $300-\mathrm{hPa}$ wind speeds over the active regions of the EAPJ and EASJ.

The MTG over a tropospheric layer is estimated as $\Delta \bar{T} / a \Delta \phi$ (Zhang and Huang 2011), where $\Delta \bar{T}$ is the difference of the vertically averaged temperature from the surface to $300 \mathrm{hPa}$ between two adjacent zonal bands, $\Delta \phi$ is the latitude distance of the two adjacent zonal bands (in units of radians) within $20^{\circ}-70^{\circ} \mathrm{N}$, and $a$ is Earth's radius.

The baroclinicity can be expressed in terms of the Eady growth rate $(\sigma)$, which is defined as in Eady (1949):

$$
\sigma=0.31\left(\frac{f}{N}\right)\left(\frac{d V}{d z}\right)
$$

where $f$ is the Coriolis parameter, $N$ is the Brunt-Väisälä frequency, $V$ is the time-mean horizontal wind velocity, and

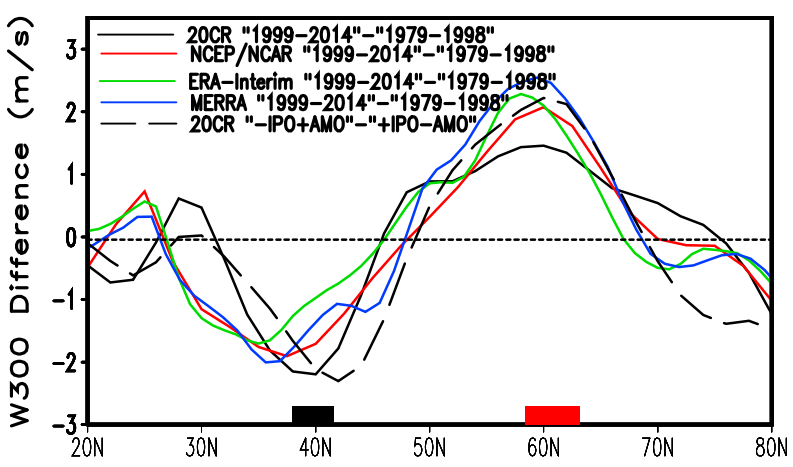

FIG. 3. The longitudinal $\left(90^{\circ}-110^{\circ} \mathrm{E}\right)$ mean $300-\mathrm{hPa}$ JJA wind speed differences between 1999-2014 and 1979-98 from the four reanalysis datasets. The black and red boxes indicate the active regions of the EASJ and EAPJ, respectively. 

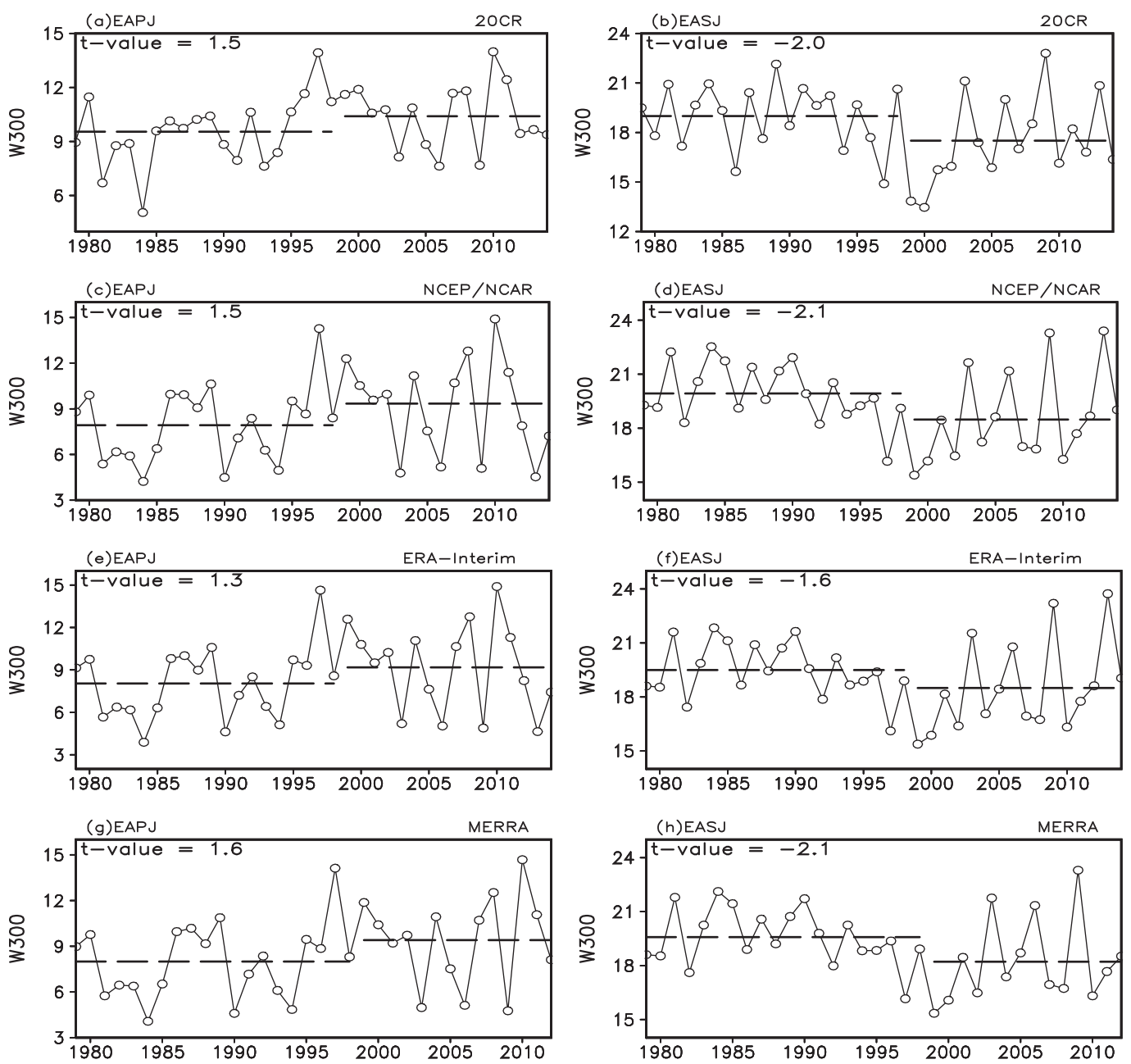

FIG. 4. The intensity index of the JJA (left) EAPJ and (right) EASJ during the period of 1979-2014 from the (a),(b) 20CR, (c),(d) NCEP-NCAR, (e),(f) ERA-Interim, and (g),(h) MERRA reanalysis datasets. The two dashed lines indicate the mean value of the intensity of the JJA EAPJ and EASJ for 1979-98 and 1999-2014. The $t$-test values are also shown in each subfigure.

$z$ is the vertical height. The $\sigma$ averaged between 700 and $850 \mathrm{hPa}$ is chosen, given that the baroclinic development primarily occurs in the lower troposphere (Lunkeit et al. 1998).
To quantitatively estimate the horizontal propagation of stationary Rossby waves, the wave activity flux vector $\mathbf{W}$ is calculated in the expression formulated by Takaya and Nakamura (2001):

$$
\mathbf{W}=\frac{p \cos \varphi}{2|\mathbf{U}|}\left(\begin{array}{l}
\frac{u}{a^{2} \cos ^{2} \varphi}\left[\left(\frac{\partial \psi^{\prime}}{\partial \lambda}\right)^{2}-\psi^{\prime}\left(\frac{\partial^{2} \psi^{\prime}}{\partial \lambda^{2}}\right)\right]+\frac{v}{a^{2} \cos \varphi}\left(\frac{\partial \psi^{\prime}}{\partial \lambda} \frac{\partial \psi^{\prime}}{\partial \varphi}-\psi^{\prime} \frac{\partial^{2} \psi^{\prime}}{\partial \lambda \partial \varphi}\right) \\
\frac{u}{a^{2} \cos \varphi}\left(\frac{\partial \psi^{\prime}}{\partial \lambda} \frac{\partial \psi^{\prime}}{\partial \varphi}-\psi^{\prime} \frac{\partial^{2} \psi^{\prime}}{\partial \lambda \partial \varphi}\right)+\frac{v}{a^{2}}\left[\left(\frac{\partial \psi^{\prime}}{\partial \lambda}\right)^{2}-\psi^{\prime}\left(\frac{\partial^{2} \psi^{\prime}}{\partial \lambda^{2}}\right)\right] \\
\frac{f_{0}^{2}}{N^{2}}\left\{\frac{u}{a \cos \varphi}\left[\frac{\partial \psi^{\prime}}{\partial \lambda} \frac{\partial \psi^{\prime}}{\partial z}-\psi^{\prime} \frac{\partial^{2} \psi^{\prime}}{\partial \lambda \partial z}\right]+\frac{v}{a}\left[\frac{\partial \psi^{\prime}}{\partial \varphi} \frac{\partial \psi^{\prime}}{\partial z}-\psi^{\prime} \frac{\partial^{2} \psi^{\prime}}{\partial \varphi \partial z}\right]\right.
\end{array}\right)
$$




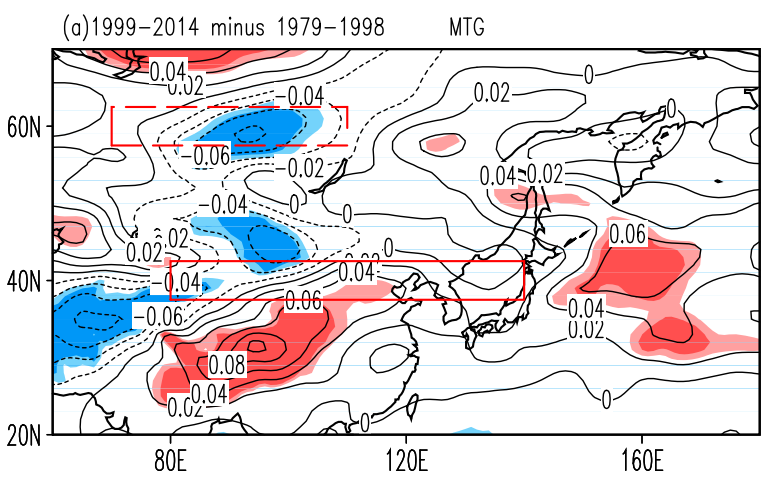

(b)1999-2014 minus 1979-1998 Eady growth rate

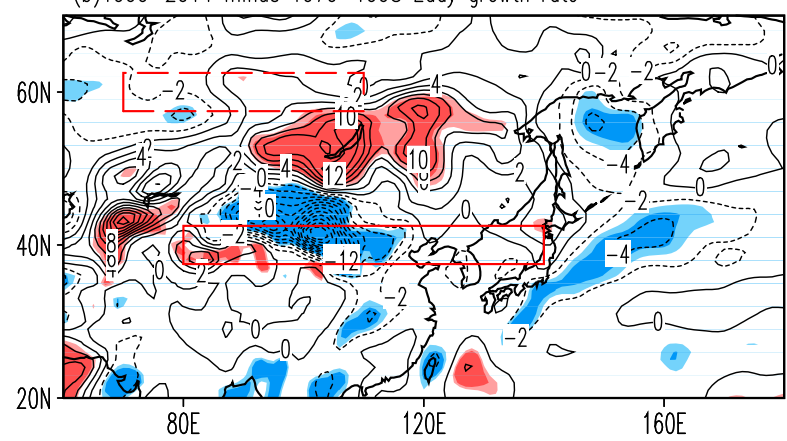

FIG. 5. The differences of the JJA (a) meridional temperature gradient (MTG; unit: $10^{-5} \mathrm{~K} \mathrm{~m}^{-1}$ ) averaged from the surface to $300 \mathrm{hPa}$ and $(\mathrm{b})$ the Eady growth rate $\left(\sigma\right.$; unit: day $\left.{ }^{-1}\right)$ between 1999-2014 and 1979-98 from the ERA-Interim reanalysis data. The red dashed (solid) box indicates the active region of the EAPJ (EASJ). The light (dark) shadings indicate that the difference is significant at the $90 \%(95 \%)$ level based on Student's $t$ test.

where $\mathbf{U}=(u, v)$ is horizontal wind vector, $p=$ (pressure $/ 1000 \mathrm{hPa}$ ) is the normalized pressure, and $\psi^{\prime}$ is the streamfunction anomaly. This flux is independent of wave phases and parallel to the group velocity in a zonally varying basic flow.

To quantitatively assess the relative contributions of the - IPO and + AMO to the recent jet changes, the multilinear regression is performed on the $300-\mathrm{hPa}$ wind speed differences between the EXP_AP and CTRL, the EXP_A and CTRL, and the EXP_P and CTRL over the active regions of the EAPJ and EASJ. For example, for the active regions of the EAPJ, the regression function among the normalized $300-\mathrm{hPa}$ wind speed differences between the EXP_A and CTRL, X1 $1_{\text {PJ(EXP_A-CTRL) }}$, the differences between the EXP_P and CTRL, X2 $2_{\text {PJ(EXP_P-CTRL) }}$, and the normalized $300-\mathrm{hPa}$ wind speed differences between the EXP_AP and CTRL, $Y_{\mathrm{PJ}\left(\mathrm{EXP} \_\mathrm{AP}-\mathrm{CTRL}\right)}$ is

$$
\begin{aligned}
Y_{\mathrm{PJ}\left(\mathrm{EXP} \_\mathrm{AP}-\mathrm{CTRL}\right)}= & \mathrm{A} 0_{\mathrm{PJ}}+\mathrm{A} 1_{\mathrm{PJ}} \times \mathrm{X} 1_{\mathrm{PJ}\left(\mathrm{EXP} \_\mathrm{A}-\mathrm{CTRL}\right)} \\
& +\mathrm{A} 2_{\mathrm{PJ}} \times \mathrm{X} 2_{\mathrm{PJ}\left(\mathrm{EXP} \_\mathrm{P}-\mathrm{CTRL}\right)},
\end{aligned}
$$

where $\mathrm{A} 0_{\mathrm{PJ}}$ is the intercept, and $\mathrm{A} 1_{\mathrm{PJ}}$ and $\mathrm{A} 2_{\mathrm{PJ}}$ are the corresponding slope of the regression for the difference between the EXP_A and CTRL, EXP_P and CTRL, respectively. The values of $\mathrm{A} 1_{\mathrm{PJ}}$ and $\mathrm{A} 2_{\mathrm{PJ}}$ can be quantified as the relative contributions of the $+\mathrm{AMO}$ and $-\mathrm{IPO}$.

Following Huang et al. (2017), we have also quantified the decadal effects of the IPO and AMO on the decadal jet changes and atmospheric circulation changes. The statistical significance of the composite analysis and regression coefficient is assessed using Student's $t$ test at the $95 \%$ and $90 \%$ confidence level.

\section{The linkage between the combinations of the IPO and AMO and the summer EAPJ and EASJ variations}

Figures $1 \mathrm{a}-\mathrm{d}$ show the $300-\mathrm{hPa}$ wind speed anomalies (relative to the 1920-2014 mean) for the four IPO and AMO phase combinations. No significant wind speed anomaly exists over the active regions of the two jets in the same phases of the IPO and AMO (+IPO + AMO, Fig. 1a; and -IPO -AMO, Fig. 1c). However, in two opposite phases of the IPO and AMO (+IPO - AMO, Fig. 1b; - IPO + AMO, Fig. 1d), a dipole anomaly pattern is remarkable over the active regions of EAPJ and EASJ. In the + IPO - AMO group (Fig. 1b), a reducedEAPJ-enhanced-EASJ anomaly is found, and is roughly opposite for the - IPO + AMO group (Fig. 1d). Particularly, this pattern is obvious in the differences between the $-\mathrm{IPO}+\mathrm{AMO}$ and $+\mathrm{IPO}-\mathrm{AMO}$ groups (Fig. 1e). The results are consistent based on other AMO and IPO indices mentioned in section 2 (figure omitted). Opposite phases of the IPO and AMO have occurred for most years during 1979-2014; the +IPO - AMO group is mostly in 1979-98 and the -IPO + AMO group in 1999-2014 (Huang et al. 2017, 2019). The differences of 300-hPa wind speeds between 1999 2014 and 1979-98 from four reanalysis datasets have been further examined (Fig. 2). An apparent dipole anomaly pattern appears over the active regions of the EAPJ and EASJ, and is mostly evident in the longitudinal mean $\left(90^{\circ}-110^{\circ} \mathrm{E}\right.$; Fig. 3). The $300-\mathrm{hPa}$ wind speed differences in longitudinal mean confirm the consistency of the wind differences between the $-\mathrm{IPO}+\mathrm{AMO}$ and + IPO - AMO groups (Fig. 3, black solid line) and between the periods of 1999-2014 and 1979-98 (Fig. 3, black dashed line) from the 20CR reanalysis data.

The variation of the intensity index of the EAPJ and EASJ has been further compared. The four reanalysis datasets show consistent results, indicating an enhanced EAPJ-reduced EASJ pattern after 1999 (Fig. 4). The decadal changes are statistically significant at the $90 \%$ 
(0)W300 vs. (-IPO)

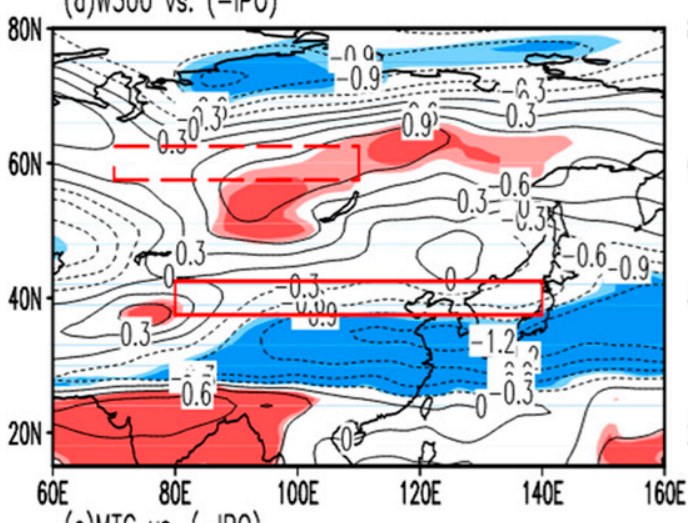

(c)MTG vs. (-IPO)
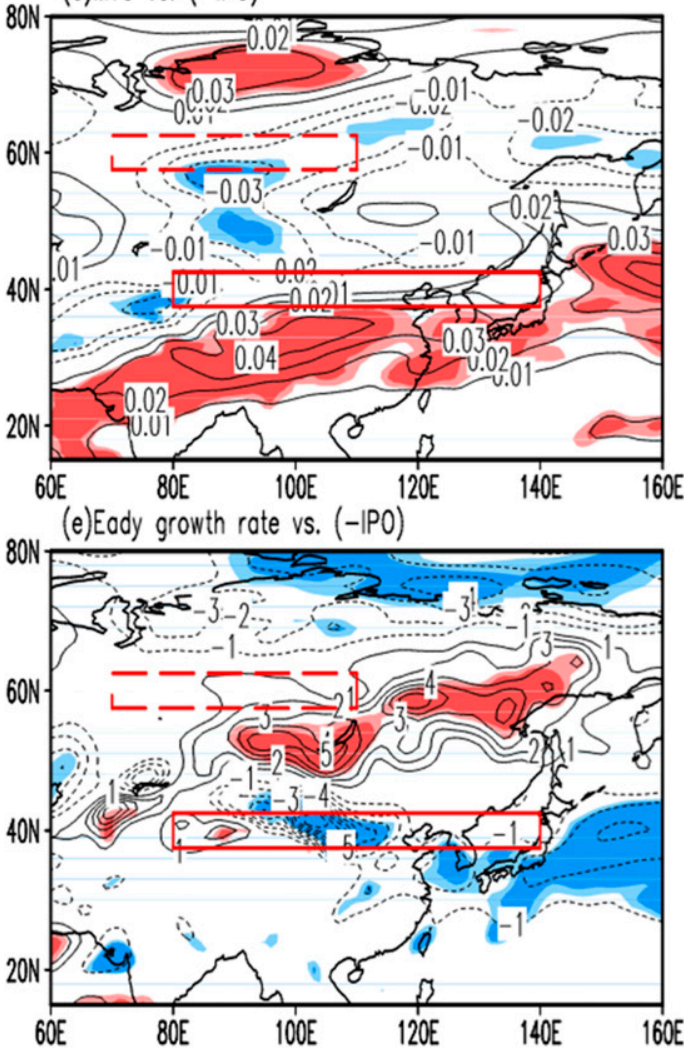

FIG. 6. Regression coefficients of (a),(b) JJA wind speed at $300 \mathrm{hPa}$ (unit: $\mathrm{m} \mathrm{s}^{-1}$ per unit index), (c),(d) the meridional temperature gradient (MTG; unit: $10^{-5} \mathrm{~K} \mathrm{~m}^{-1}$ per unit index) averaged from the surface to $300 \mathrm{hPa}$, and (e),(f) the Eady growth rate $\left(\sigma\right.$; unit: day ${ }^{-1}$ per unit index) against (a),(c),(e) the unsmoothed IPO index (multiplied by -1 , indicating the negative phase of the IPO; unit: $\mathrm{m} \mathrm{s}^{-1}$ per unit index) and (b),(d),(f) the unsmoothed AMO index (unit: $\mathrm{m} \mathrm{s}^{-1}$ per unit index) during 1979-2014 from the ERAInterim reanalysis data. The red dashed (solid) box indicates the active region of the EAPJ (EASJ). The light (dark) shading indicates that the regression coefficient is significant at the $90 \%(95 \%)$ level based on Student's $t$ test. level, particularly for the variation of the EASJ ( $t$-test value in Fig. 4). Thus, we conclude that the EAPJ and EASJ have strengthened and weakened from 197998 to $1999-2014$, respectively. The recent decadal jet changes mostly resemble the differences between the $-\mathrm{IPO}+\mathrm{AMO}$ and the $+\mathrm{IPO}-\mathrm{AMO}$ groups during 1979-2014. Considering the good performance of
(b)W300 vs. (AMO)

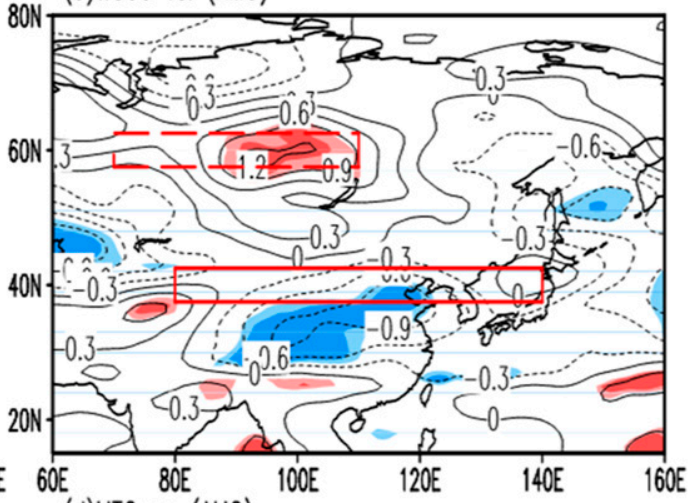

(d)MTG vs. (AMO)

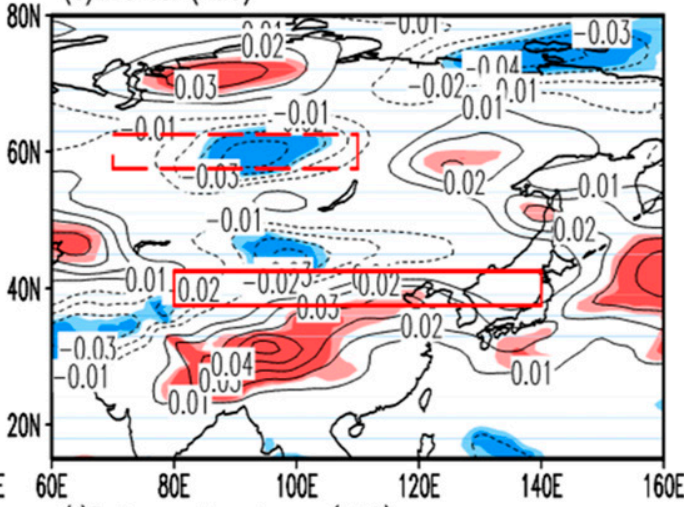

(f)Eody growth rote vs. (AMO)

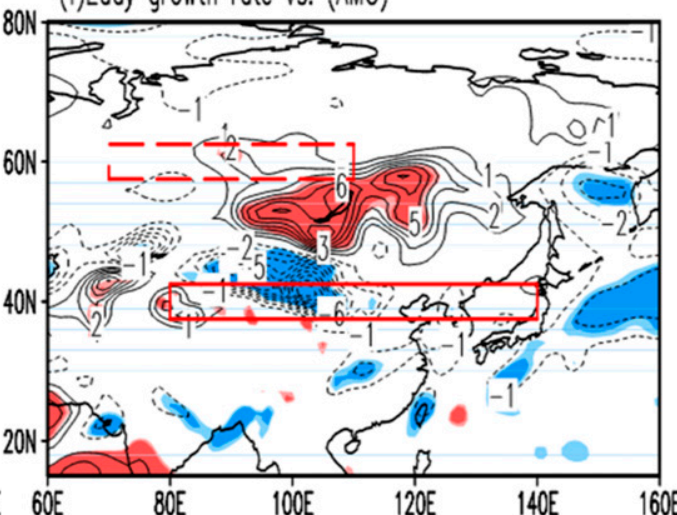

quantifying atmospheric circulations over East Asia (Huang et al. 2016; Zhu et al. 2017), the ERAInterim reanalysis data are chosen in the following analysis. Additionally, we focused on the two periods of 1979-98 and 1999-2014, which largely represent the two opposite phases of the IPO and AMO (the + IPO - AMO and - IPO + AMO groups). 
(o)W300 Change Contribution by (IPO)

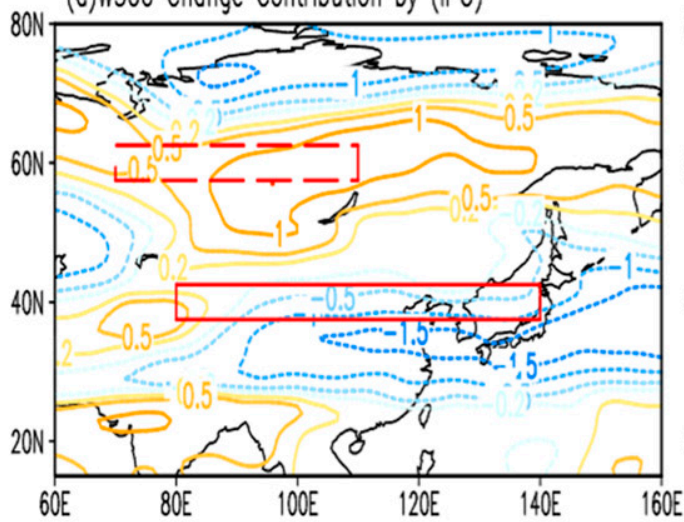

(c)MTG Chonge Contribution by (IPO)

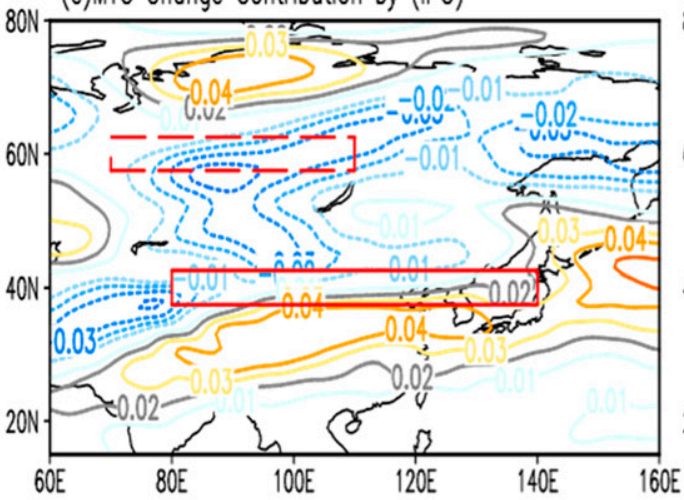

(e)Eady growth rote Change Contribution by (IPO)

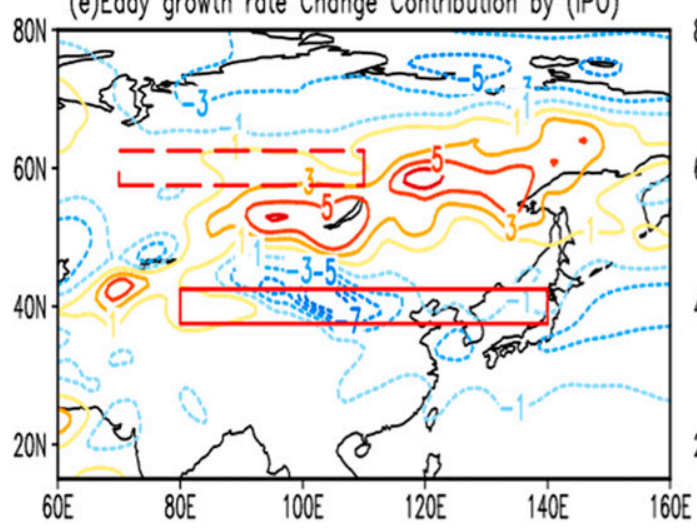

(b)W300 Chonge Contribution by (AMO)

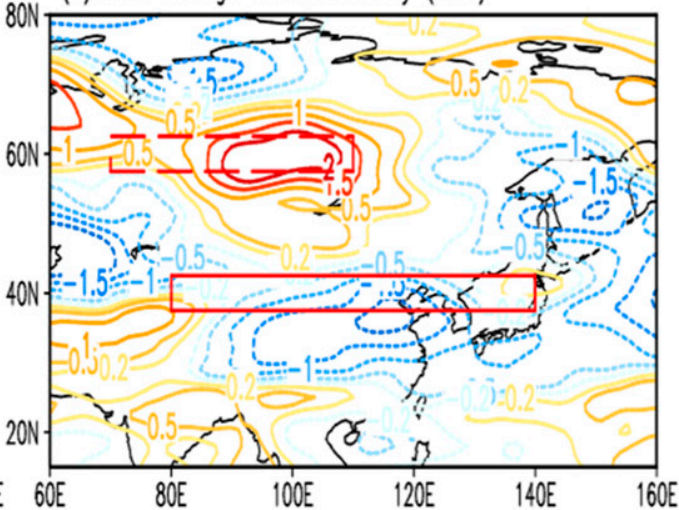

(d)MTG Change Contribution by (AMO)

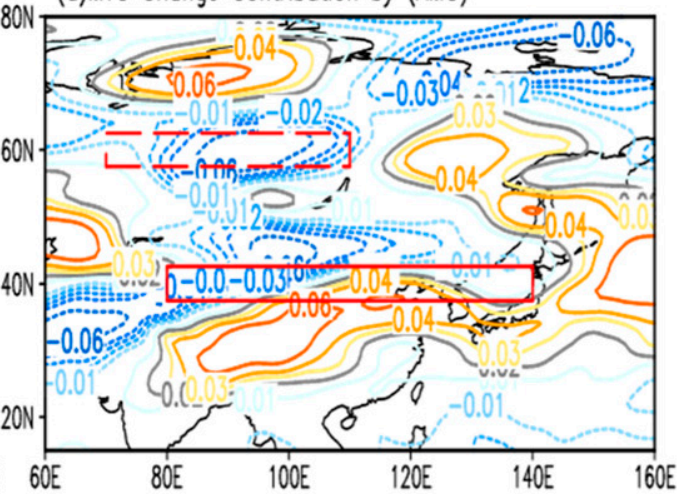

FIG. 7. As in Fig. 6, but for the decadal changes in (a),(b) 300-hPa wind speed (unit: $\mathrm{m} \mathrm{s}^{-1}$ per unit index), (c),(d) meridional temperature gradient (MTG; unit: $10^{-5} \mathrm{~K} \mathrm{~m}^{-1}$ per unit index) averaged from the surface to $300 \mathrm{hPa}$, and (e),(f) Eady growth rate ( $\sigma$; unit: day ${ }^{-1}$ per unit index) from 1979-98 to 1999-2014 estimated by multiplying the regression coefficients shown in Fig. 6 by the decadal changes in the (a),(c),(e) IPO and (b),(d),(f) AMO index from the ERA-Interim reanalysis data.

\section{Mechanisms for the associated summer EAPJ and EASJ variations with the opposite phases of the IPO and AMO}

\section{a. Diagnostic analysis}

Figure 5 shows the MTG and $\sigma$ differences between the periods 1999-2014 and 1979-98. In the Northern
Hemisphere, a negative MTG anomaly strengthens the MTG, and vice versa (Zhang et al. 2006; Zhang and Huang 2011). As shown in Fig. 5a, the positive and negative MTG anomalies mainly locate over the active regions of the EASJ and EAPJ, respectively. The negative MTG anomaly over the EAPJ would strengthen the MTG and therefore intensify the EAPJ, according to the thermal wind principle, while 


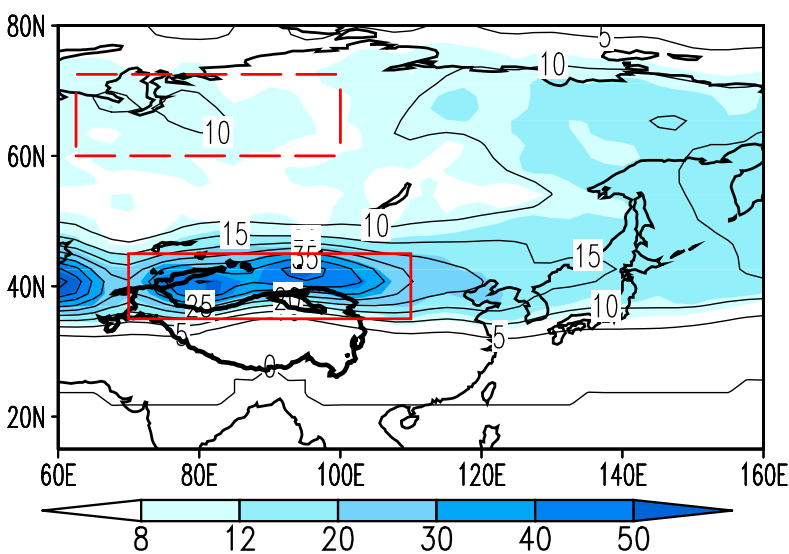

FIG. 8. Climatological number of JJA jet cores at $300 \mathrm{hPa}$ (unit: day) in the CTRL run. The red dashed (solid) box indicates the active region of the EAPJ, $60^{\circ}-72.5^{\circ} \mathrm{N}, 62.5^{\circ}-100^{\circ} \mathrm{E}\left(\mathrm{EASJ} ; 35^{\circ}-\right.$ $\left.45^{\circ} \mathrm{N}, 70^{\circ}-110^{\circ} \mathrm{E}\right)$. The thick black solid contour indicates the boundary of the Tibetan Plateau.

the positive MTG anomaly would weaken the EASJ. In particular, the MTG anomaly over EAPJ is more significant than that over EASJ. However, in Fig. 5b, the $\sigma$ differences show a negative anomaly pattern over the EASJ and may weaken the EASJ. Comparing Figs. 5a and 5b, it can be inferred that the variation of the EAPJ may be closely associated with the MTG anomaly, whereas that of EASJ may be closely related with the $\sigma$ anomaly. Actually, we should not ignore the negative MTG anomalies over the regions between the EAPJ and EASJ (around $40^{\circ}-50^{\circ} \mathrm{N}$ ), where the positive $\sigma$ anomalies are also indicated. These anomalies may also intensify the westerlies over there (Fig. 2).

To analyze the relationship of recent jet changes with the variation of IPO and AMO, the $300-\mathrm{hPa}$ wind speed is regressed against the negative IPO (Fig. 6a) or the positive AMO index (Fig. 6b) during 1979-2014. Associated with the -IPO (Fig. 6a), a quaternary wind anomaly pattern occurs along the $80^{\circ}-120^{\circ} \mathrm{E}$ longitude bands from $20^{\circ}$ to $80^{\circ} \mathrm{N}$ including the positive (negative) anomalies over the active regions of the EAPJ (EASJ). Associated with the +AMO (Fig. 6b), a dipole wind anomaly exists over the active regions of the two jets. These wind anomalies (Figs. 6a,b) represent the enhanced EAPJ and reduced EASJ. The results imply that, associated with the $-\mathrm{IPO}$ and $+\mathrm{AMO}$, the wind speed anomalies are more significant over the EAPJ than over the EASJ. The variations of the MTG and $\sigma$ regressed against the negative IPO or positive AMO index during 1979-2014 are further shown in Figs. $6 \mathrm{c}$ and $6 \mathrm{~d}$, indicating the enhanced and reduced MTG anomalies over the active regions of the EAPJ and EASJ. Associated with the -IPO (Fig. 6e) and + AMO (Fig. 6f), a significant negative $\sigma$ anomaly also occurs over the regions along $40^{\circ} \mathrm{N}$, which would weaken the EASJ. We noticed that the MTG and $\sigma$ anomalies associated with the IPO and AMO are quite significant over the active regions of the EAPJ and EASJ, and also similar to the decadal changes in the MTG and $\sigma$ anomalies (Fig. 5).

Additionally, we have quantified the decadal effects of the IPO and the AMO in the jets, MTG, and $\sigma$ changes, which are shown in Fig. 7. For the recent jet changes, the regression coefficients in Fig. 6 have been multiplied by the decadal changes in the IPO and AMO indices between 1999-2014 and 1979-98. A positive wind anomaly is over the EAPJ and a negative wind anomaly is found over the EASJ (Figs. 7a,b). This enhanced EAPJ-reduced EASJ pattern can also be proved by the decadal changes of the MTG and $\sigma$ (Figs. 7c-f), which are roughly similar to the regressed MTG and $\sigma$ patterns (Figs. $6 \mathrm{c}-\mathrm{f}$ ). These results have indicated the linkage of the decadal MTG and $\sigma$ changes in the two periods and the changes in the IPO and AMO phase. Moreover, it is suggested that the associated with the IPO and AMO, the MTG and $\sigma$ variations can explain the intensity changes of the two jets.

Because of the close correlation relationship between the IPO and AMO indices, with a correlation coefficient of -0.56 in the period of 1979-2014, we have further used the partial regression to understand the individual roles of the IPO and AMO with regard to the summer jet variations. The partial regression results (figure omitted) are consistent with the regression results (Fig. 6). Therefore, the diagnostic analysis above supports that both the - IPO and + AMO would benefit the enhanced EAPJ and weakened EASJ after 1999. Nevertheless, due to the high correlation between the IPO and AMO, the effects of the IPO and AMO on the jet changes may overlap. Thus, model experiments are necessary to confirm this relationship, which will be shown in section $4 b$.

\section{b. Model results}

Based on the occurrence number of jet cores in the CTRL run, the active regions of the two jests have been reselected for model simulations, as $60^{\circ}-72.5^{\circ} \mathrm{N}, 62.5^{\circ}-$ $100^{\circ} \mathrm{E}$ for the EAPJ (red dashed box) and $35^{\circ}-45^{\circ} \mathrm{N}, 70^{\circ}-$ $110^{\circ} \mathrm{E}$ for the EASJ (red solid box) in Fig. 8. Although there is a deviation with the reanalysis data (Fig. 1 in Huang et al. 2014), a dipole wind anomaly can be found over the EAPJ and EASJ in the EXP_All experiment (Fig. 9a). This dipole anomaly favors the enhanced EAPJ and reduced EASJ (red dashed line in Fig. 10), which is quantitatively consistent with the ERA-Interim results (black solid line in Fig. 10). Even though the changes in the simulation are less than that in the reanalysis, the model has the ability to qualitatively capture the intensity change of the two jets. Therefore, the model simulations can be used to figure out the mechanisms of the intensity changes of the two jets. 

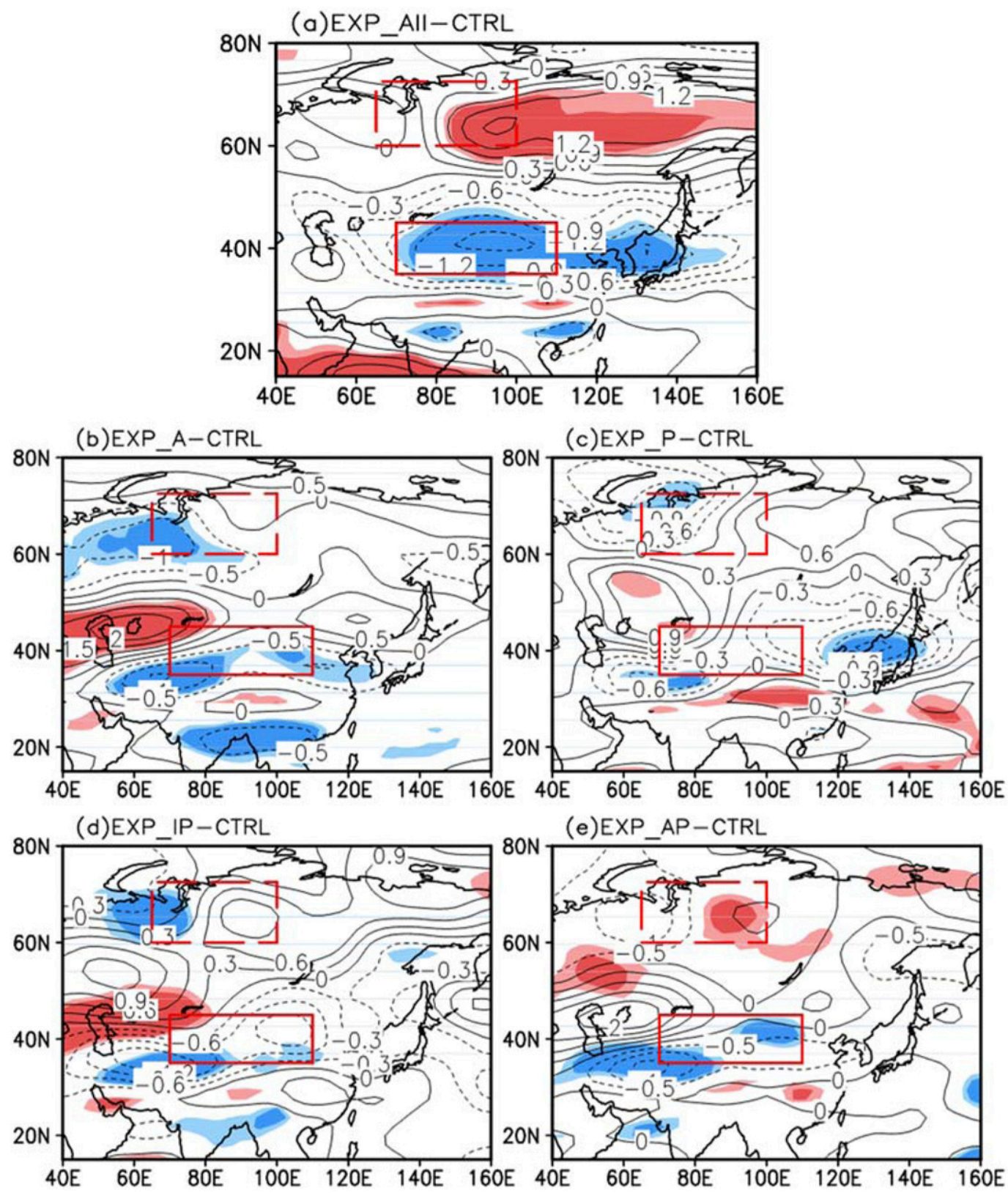

FIG. 9. The 300-hPa JJA wind speed differences (unit: $\mathrm{m} \mathrm{s}^{-1}$ ) between (a) EXP_A and CTRL, (b) EXP_P and CTRL, (c) EXP_AP and CTRL, and (d) EXP_IP and CTRL. The red dashed (solid) box indicates the active region of the EAPJ (EASJ). The light (dark) shadings indicate that the difference is significant at the $90 \%(95 \%)$ level based on Student's $t$ test.

The wind speed differences between the four sensitivity experiments and the CTRL run are compared in Figs. 9b-e. The differences between the EXP_A, EXP_P, EXP_IP, and the CTRL run show similar patterns, with a reduced EAPJ-reduced EASJ anomaly (Figs. 9b-d). Combined with the North Atlantic and Pacific SST forcing, the EXP_AP experiment shows an enhanced EAPJ-weakened EASJ anomaly (Fig. 9e). The longitudinal-mean variation has further confirmed this anomaly (red solid line in Fig. 10). Similarly, it is also qualitatively consistent with the differences between 1999-2014 and 1979-98 in the reanalysis data (black solid line in Fig. 10). As in Huang et al. (2019), but for summer, the model simulations have emphasized that the combination of -IPO + AMO favors the jet changes more than the individual -IPO or + AMO. Meanwhile, significant negative (positive) MTG anomalies over the EAPJ (EASJ) region tend to strengthen (weaken) the 


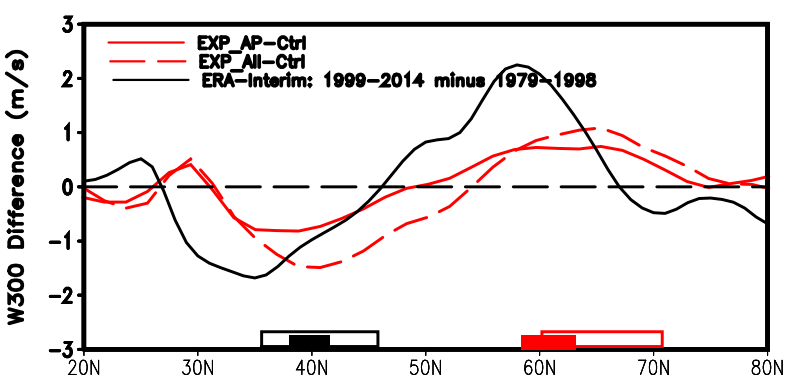

FIG. 10. The $70^{\circ}-100^{\circ} \mathrm{E}$ mean $300-\mathrm{hPa}$ JJA wind speed differences (unit: $\mathrm{m} \mathrm{s}^{-1}$ ) between EXP_AP and CTRL (red solid line), EXP_All and CTRL (red dashed line), and $90^{\circ}-100^{\circ} \mathrm{E}$ mean 300 hPa JJA wind speed differences between 1999-2014 and 1979-98 from ERA-Interim (black line). The red (black) solid box indicates the active region of the EAPJ (EASJ) from ERA-Interim reanalysis data, while the red (black) hollow box indicates the active regions of the EAPJ (EASJ) from the model simulations.

MTG (Fig. 11a). Robust positive (negative) $\sigma$ anomalies are also seen over the active regions of the EAPJ (EASJ) (Fig. 11b). As a result, the EAPJ enhances and EASJ reduces (Figs. 9e and 10). In all, the results have revealed that in summer, the combinations of negative IPO and positive AMO will intensify the EAPJ and weaken the EASJ, via the variations of the MTG and $\sigma$.

\section{Relative contributions and impact pathways of the -IPO and + AMO to changes of the EAPJ and EASJ}

Since the IPO and AMO are highly correlated, the relative contributions of the - IPO and + AMO to the jet changes should be analyzed by the model simulations. We assumed that the contributions of the - IPO and + AMO would be linearly linked to the combination of $-\mathrm{IPO}+\mathrm{AMO}$ on the jet variations. Consequently, the multilinear regression is used to quantify the relative contributions of the -IPO and + AMO to the EAPJ and EASJ variations, which are shown in Figs. 12a and 12c, respectively. For comparison, the normalized $300-\mathrm{hPa}$ wind speed differences between the EXP_AP and CTRL runs over the active regions of the EAPJ and EASJ are shown in Figs. 12b and 12d, respectively. The estimated $300-\mathrm{hPa}$ summer wind speeds and differences between EXP_AP and CTRL are quantitatively consistent, and the two regression equations are significant at the $99 \%$ level. Since the slope of the regression equation for the difference between EXP_P and CTRL is higher than that between EXP_A and CTRL, we considered that the -IPO may play a more important role in the jet changes than the $+\mathrm{AMO}$, particularly for the EASJ changes. We should notice that the role of the - IPO + AMO combination may not be linearly linked with the individual roles of the - IPO and + AMO. The complicated nonlinear interaction between the - IPO and + AMO results in the differences between the multiregression and the decadal changes of the wind speeds. The interbasin teleconnections and tropicalextratropical teleconnections have been recently noticed at the decadal scale (Cassou et al. 2018; Cai et al. 2019).

In fact, the SST anomalies over the Atlantic and Pacific Oceans would modulate the atmospheric circulations, and therefore the variations in the MTG, the Eady growth rate and eventually the jets. The anomalous atmospheric circulation anomalies between EXP_ AP and CTRL have been further analyzed. As shown in Fig. 13a, a negative sea level pressure (SLP) and a "- +" dipole anomaly occur over the North Atlantic and the Pacific Ocean, respectively. At $850 \mathrm{hPa}$ (Fig. 13b), the two anomalies persisted over the Pacific Ocean and North Atlantic Ocean. By the hydrostatic and geostrophic equilibriums, the positive geopotential height would trigger an anticyclonic anomaly in the upper layer (Sun et al. 2015). These triggered anticyclonic anomalies at $500 \mathrm{hPa}$ (Fig. 13c) and $300 \mathrm{hPa}$ (Fig. 13d) are significant over the Atlantic Ocean and the western part of the Pacific Ocean. In addition, the positive pressure anomaly covers most of the low-latitude regions and the North Atlantic. In particular, the westerly and easterly wind anomaly is over the active region of the EAPJ and EASJ, which would intensify the EAPJ and weaken the EASJ.

To investigate the possible propagation, the $300-\mathrm{hPa}$ stationary Rossby-wave activity fluxes and geopotential height anomaly fields in the entire extratropical Northern Hemisphere associated with the -IPO + AMO combination are analyzed (Fig. 14). The significant wave activity flux anomalies extend eastward from the North Atlantic to East Asia along $60^{\circ} \mathrm{N}$, where the EAPJ is located. Meanwhile, significant wave activity flux anomalies extend westward from the northern Pacific to East Asia along $40^{\circ} \mathrm{N}$. The pathways of stationary Rossby waves are associated with positive height anomalies (anomalous anticyclones) over the regions between the EAPJ and the EASJ. The zonal winds to the north of the anomalous anticyclone have increased, corresponding to the enhanced EAPJ. Meanwhile, the zonal winds to the south of the anomalous anticyclones have decreased, related to the reduced EASJ. The results suggest that $+\mathrm{AMO}$ will intensify the EAPJ via the wave activity flux along $60^{\circ} \mathrm{N}$, while the -IPO will weaken the EASJ via the wave activity flux along $40^{\circ} \mathrm{N}$.

\section{Conclusions and discussion}

The impacts of different combinations of the AMO and IPO on the EAPJ and EASJ in the boreal summer were examined in this study. The responses of the EAPJ and 

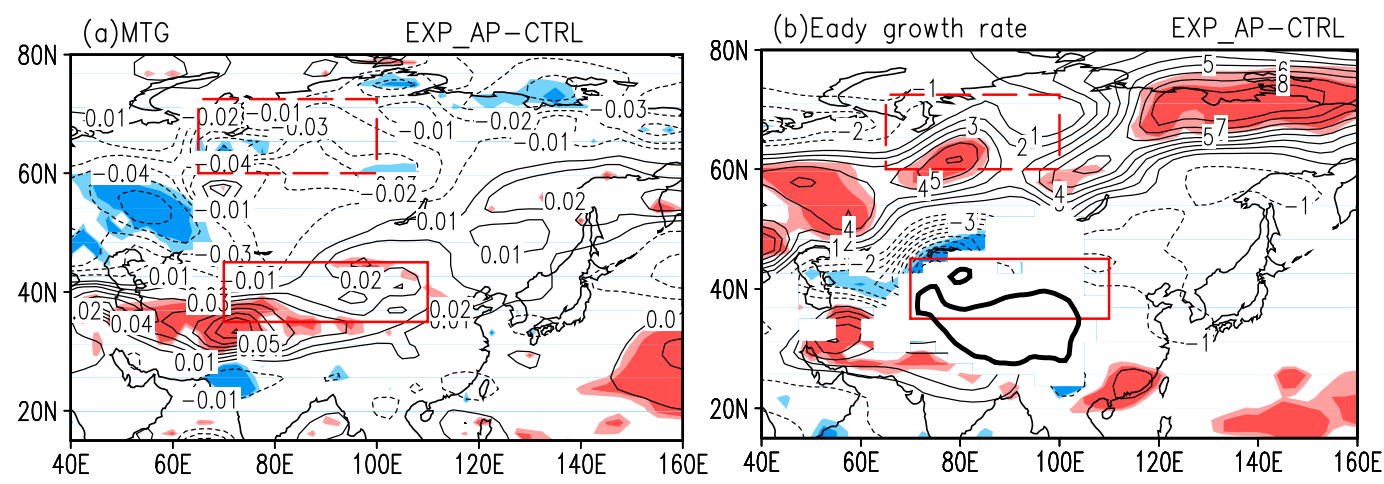

FIG. 11. The JJA (a) meridional temperature gradient (MTG; unit: $10^{-5} \mathrm{~K} \mathrm{~m}^{-1}$ ) averaged from the surface to $300 \mathrm{hPa}$ and (b) Eady growth rate differences $\left(\sigma\right.$; unit: day $\left.{ }^{-1}\right)$ between EXP_AP and CTRL. The red dashed (solid) box indicates the active region of the EAPJ (EASJ). The light (dark) shadings indicate that the difference is significant at the $90 \%(95 \%)$ level based on Student's $t$ test. The thick black solid contour in (b) indicates the boundary of the Tibetan Plateau.

EASJ in the opposite phases of the IPO and AMO are significant but show opposite anomalies. In the - IPO + AMO combination, significant positive (negative) anomalies occur over the active regions of the EAPJ (EASJ), and thus intensify the EAPJ and weaken the EASJ, and vice versa in the combination +IPO - AMO. Particularly, this pattern is also evident in the jet differences (spatial pattern and the longitudinal mean differences) between the period of 1999-2014 (-IPO + AMO) and 1979-98 (+IPO -AMO). Since 1999, the IPO- and AMOassociated SST anomalies have enhanced and reduced the MTG and $\sigma$ over the EAPJ and EASJ, respectively,

\section{(a)Multi-regression(PJ)}

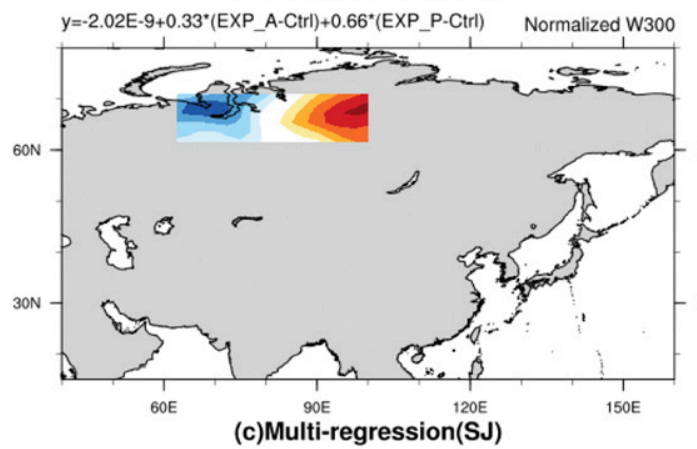

(c)Multi-regression(S J)

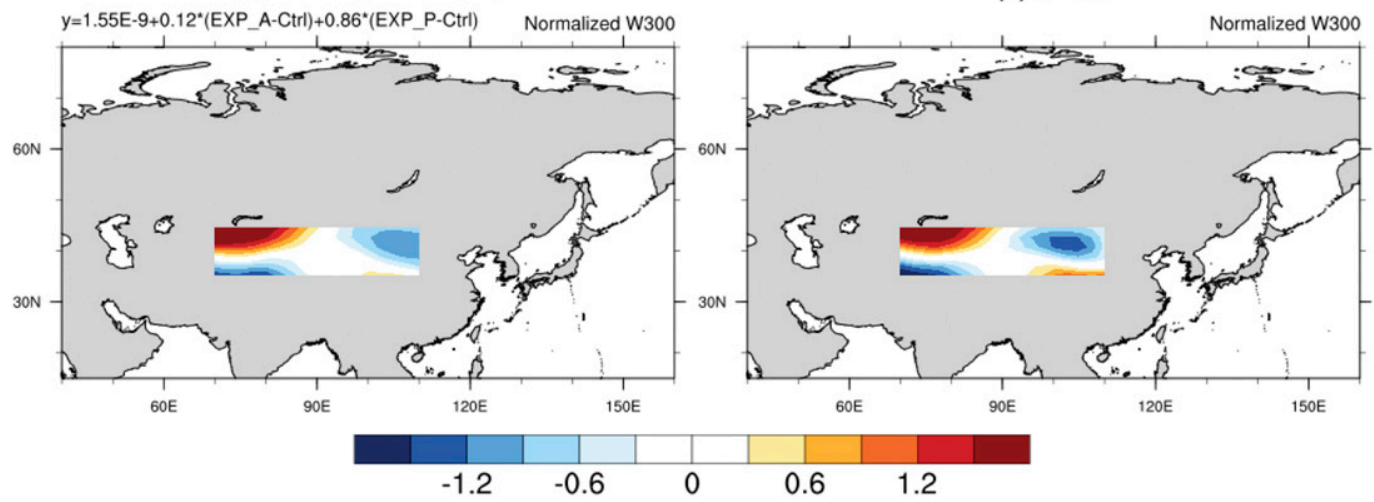

FIG. 12. The estimated 300-hPa JJA wind speed differences against (a),(c) the normalized wind speed differences between EXP_A and CTRL and EXP_P and CTRL and (b),(d) the normalized 300-hPa JJA wind speed differences between EXP_AP and CTRL, for the active region of the (a),(b) EAPJ and (c),(d) EASJ.
(b)AP-Ctrl

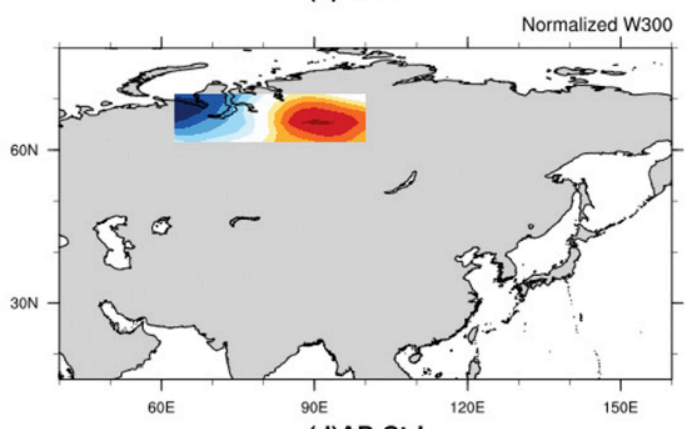

(d)AP-Ctr 

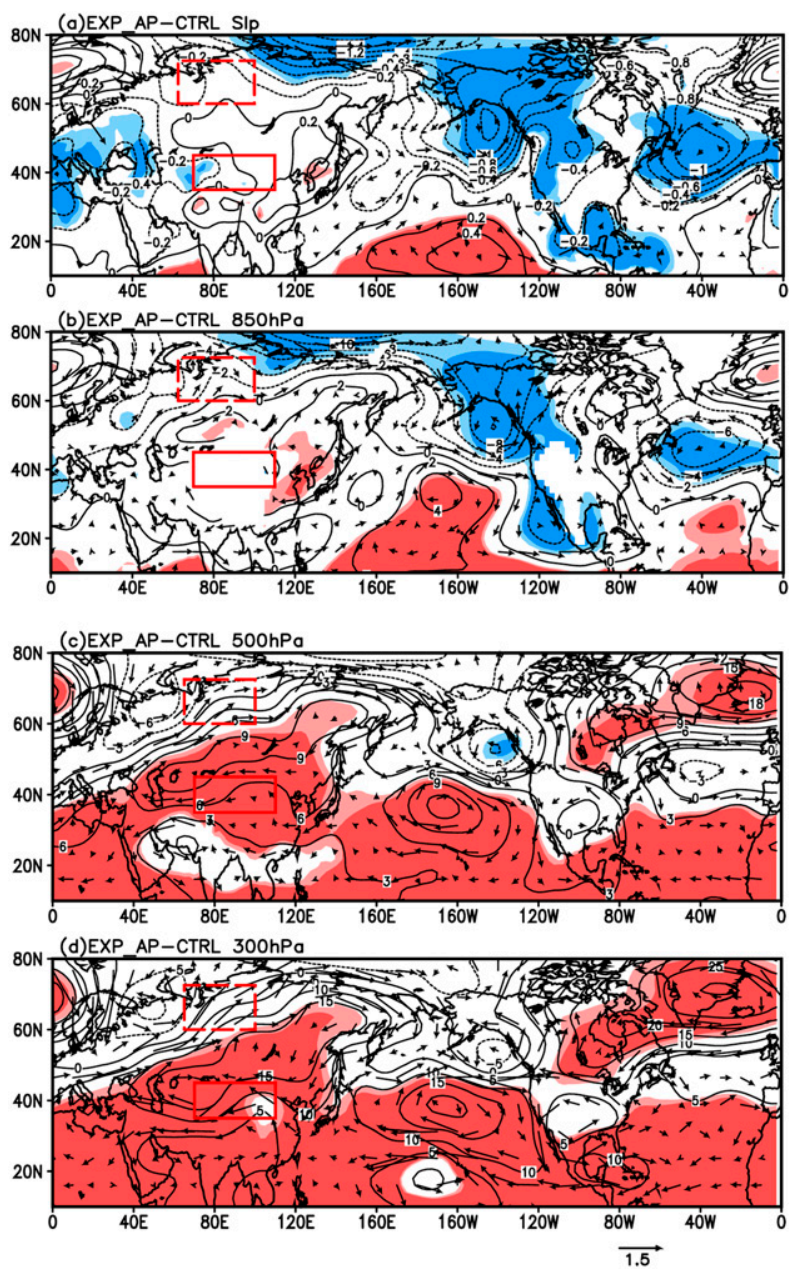

FIG. 13. (a) The JJA sea level pressure (unit: hPa) and 1000$\mathrm{hPa}$ wind anomalies (unit: $\mathrm{m} \mathrm{s}^{-1}$ ), and the geopotential height (unit: gpm) and wind anomalies (unit: $\mathrm{m} \mathrm{s}^{-1}$ ) at (b) 850 , (c) 500 , and (d) $300 \mathrm{hPa}$ between EXP_AP and CTRL. The red dashed (solid) box indicates the active region of the EAPJ (EASJ). The light (dark) shadings indicate that the difference is significant at the $90 \%(95 \%)$ level based on Student's $t$ test.

resulting in an enhanced EAPJ-reduced EASJ anomaly. Particularly, the variation of the EAPJ may be closely associated with the MTG anomaly, while that of EASJ may be closely related with the $\sigma$ anomaly. The decadal changes in 300-hPa wind speeds, MTG, and $\sigma$ are further linked to the recent phase changes of the IPO and AMO.

Five CESM1.2.0 model experiments forced by different combinations of the SST anomalies of 1999-2014 (relative to 1979-98) have confirmed the relation between the recent phase changes in the IPO and AMO and the jets, which is revealed in the reanalysis data. Simulations suggest that $-\mathrm{IPO},+\mathrm{AMO}$, or the combined effects of -IPO and the warming over the Indian Ocean would weaken both

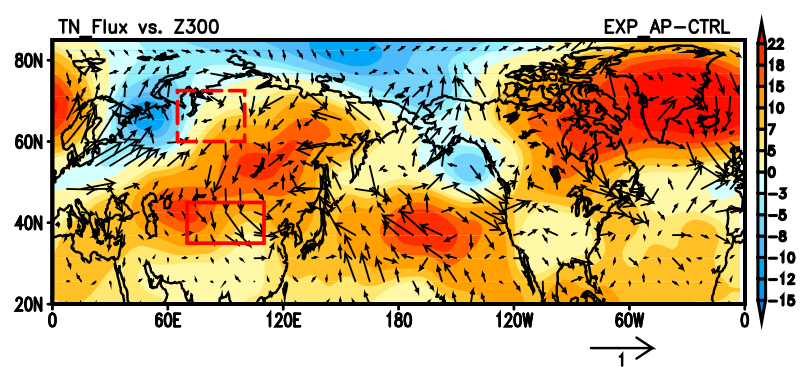

FIG. 14. The 300-hPa JJA geopotential height anomalies (shaded; unit: gpm) and wave activity flux anomalies (vector; unit: $\mathrm{m}^{2} \mathrm{~s}^{-2}$ ) between EXP_AP and CTRL. The red dashed (solid) box indicates the active region of the EAPJ (EASJ).

the EAPJ and EASJ. Particularly, only the - IPO + AMO combination would lead to an enhanced EAPJ and reduced EASJ in the model, as well as the variation of the MTG and $\sigma$.

The relative contributions and impact pathways of the $-\mathrm{IPO}$ and $+\mathrm{AMO}$ to the jet changes have further examined by the simulations. The multilinear regression has indicated that the -IPO plays a more important role than the +AMO, particularly for the reduced EASJ. The atmospheric circulations and the stationary Rossby-wave flux activities are examined in the model experiment forced with the - IPO + AMO-like SST anomalies. In the upper layer, a positive anomalous center of geopotential height appears over the North Atlantic and low-latitude regions, accompanied by the westerly and easterly anomalies in the active regions of the EAPJ and EASJ, respectively. Correspondingly, one Rossby wave train propagated eastward from North Atlantic along the middle and high latitudes. Another Rossby wave train extends westward from the northern Pacific to East Asia along $40^{\circ} \mathrm{N}$.

As mentioned in the abstract and introduction, our previous studies (Huang et al. 2017, 2019) have analyzed the recent changes in winter precipitation over eastern China, the EAPJ and EASJ, the combinations of the AMO and IPO, and the relationships among them, mostly focused on the dynamical analysis. However, the quantitatively analysis for the relative contributions of the AMO and IPO and the impact pathways are absent but needed. In this study, we have focused on the quantitative contributions of the two SST anomalies (-IPO and + AMO) to the summer variations in the two jets. These studies have drawn a fuller picture that links different combinations of the AMO and IPO and the concurrent variations of the EAPJ and EASJ. Our results show that, both in the boreal summer and winter, the responses of the EAPJ and EASJ are evident in the opposite phases of the IPO and AMO (e.g., the - IPO + AMO and the + IPO - AMO groups). The differences indicated that the jet changes are 


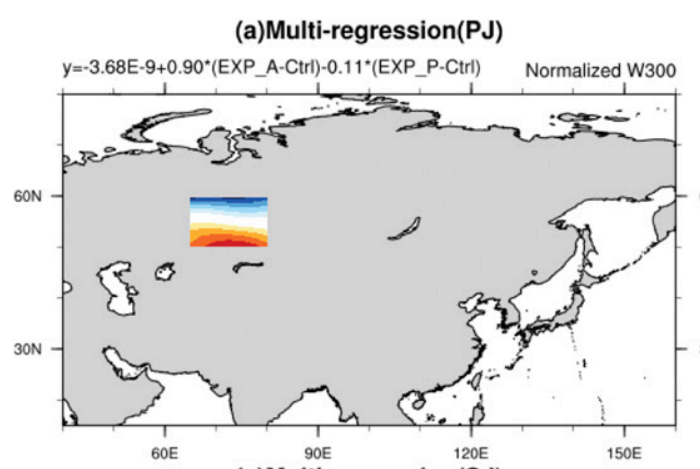

(c)Multi-regression(SJ)

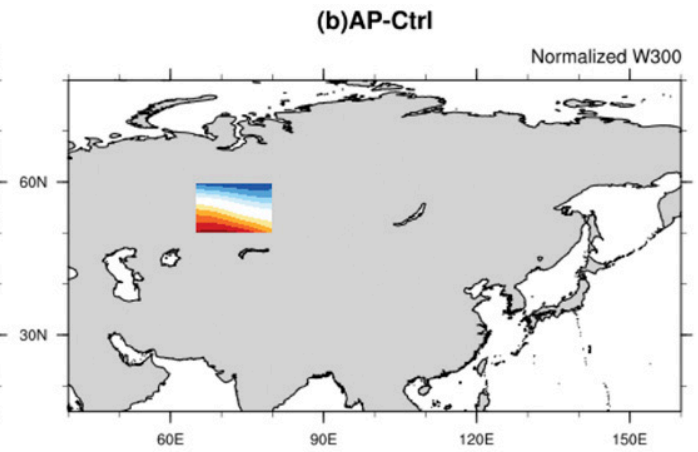

(b)AP-CtrI

(d)AP-Ctrl
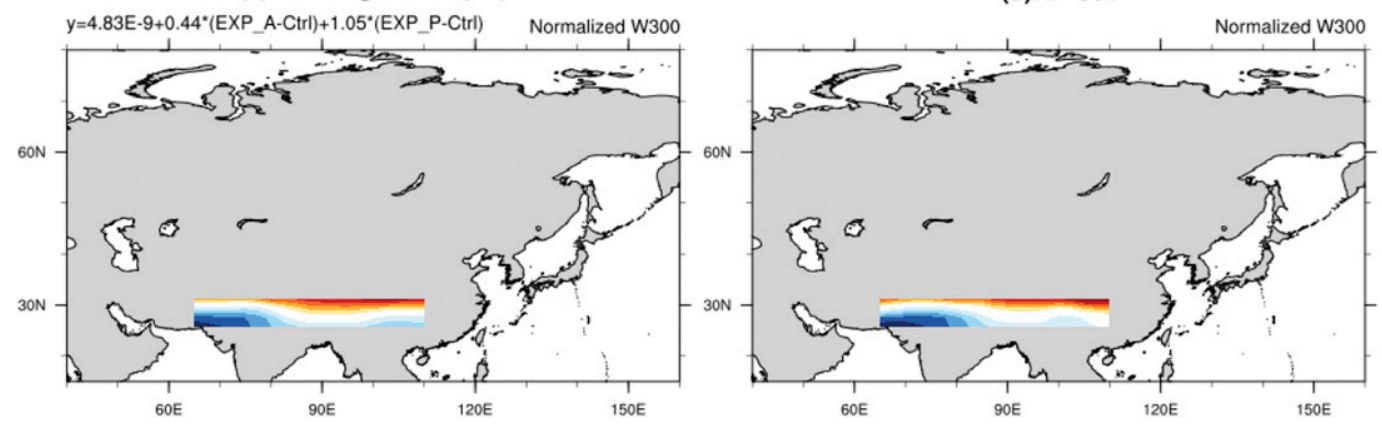

FIG. 15. As in Fig. 12, but for the (a),(c) estimated and (b),(d) normalized 300-hPa wind speed differences for the active region of the (a),(b) EAPJ $\left(50^{\circ}-60^{\circ} \mathrm{N}, 65^{\circ}-80^{\circ} \mathrm{E}\right)$ and (c),(d) EASJ $\left(25^{\circ}-32^{\circ} \mathrm{N}, 65^{\circ}-110^{\circ} \mathrm{E}\right)$ in boreal winter.

in the aspect of intensity variations in summer but in the shift variations in winter. Additionally, the relative contributions of - IPO and + AMO are different in the two seasons, as - IPO favors the intensity concurrent variations in summer, particularly for the variation of the EASJ, while + AMO (-IPO) benefits the shift of the EAPJ (EASJ) in winter (Fig. 15).

Acknowledgments. This study is jointly sponsored by the National Key Research and Development Program of China (Grant 2016YFA0600701), the National Natural Science Foundation of China (Grants 41930960 and 41775073) and the Jiangsu Collaborative Innovation Center for Climate Change.

\section{REFERENCES}

Cai, W., and Coauthors, 2019: Pantropical climate interactions. Science, 363, eaav4236, https://doi.org/10.1126/science.aav4236.

Cassou, C., Y. Kushnir, E. Hawkins, A. Pirani, F. Kucharski, I.-S. Kang, and N. Caltabiano, 2018: Decadal climate variability: Predictability challenges and opportunities. Bull. Amer. Meteor. Soc., 99, 479-490, https://doi.org/10.1175/BAMS-D-16-0286.1.

Compo, G. P., and Coauthors, 2011: The Twentieth Century Reanalysis Project. Quart. J. Roy. Meteor. Soc., 137, 1-28, https://doi.org/10.1002/qj.776.

Dai, A., 2013: The influence of the inter-decadal Pacific oscillation on US precipitation during 1923-2010. Climate Dyn., 41, 633646, https://doi.org/10.1007/s00382-012-1446-5.
Dee, D. P., and Coauthors, 2011: The ERA-Interim reanalysis: Configuration and performance of the data assimilation system. Quart. J. Roy. Meteor. Soc., 137, 553-597, https:// doi.org/10.1002/qj.828.

Dong, B., and A. Dai, 2015: The influence of the Interdecadal Pacific Oscillation on temperature and precipitation over the globe. Climate Dyn., 45, 2667-2681, https://doi.org/10.1007/s00382-015-2500-x.

Dong, M., J. R. Yu, and S. T. Gao, 1999: A study on the variations of the westerly jet over East Asia and its relation with the tropical convective heating (in Chinese). Chin. J. Atmos. Sci., 23, 62-70.

Eady, E. T., 1949: Long waves and cyclone waves. Tellus, 1, 33-52, https://doi.org/10.1111/J.2153-3490.1949.TB01265.X.

Enfield, D. B., A. M. Mestas-Nuñez, and P. J. Trimble, 2001: The Atlantic multidecadal oscillation and its relation to rainfall and river flows in the continental U.S. Geophys. Res. Lett., 28, 2077-2080, https://doi.org/10.1029/2000GL012745.

Gelaro, R., and Coauthors, 2017: The Modern-Era Retrospective Analysis for Research and Applications, version 2 (MERRA-2). J. Climate, 30, 5419-5454, https://doi.org/10.1175/JCLI-D-160758.1.

He, C., A. Lin, D. Gu, C. Li, B. Zheng, and T. Zhou, 2016: Interannual variability of eastern China summer rainfall: The origins of the meridional triple and dipole modes. Climate Dyn., 48, 683-696, https://doi.org/10.1007/S00382-016-3103-X.

Horinouchi, T., and A. Hayashi, 2017: Meandering subtropical jet and precipitation over summertime East Asia and the northwestern Pacific. J. Climate, 74, 1233-1247, https://doi.org/ 10.1175/JAS-D-16-0252.1.

Huang, D., M. Takahashi, and Y. Zhang, 2011: Analysis of the Baiu precipitation and associated circulations simulated by the 
MIROC coupled climate system model. J. Meteor. Soc. Japan, 89, 625-636, https://doi.org/10.2151/jmsj.2011-603.

—, J. Zhu, Y. Zhang, and A. Huang, 2014: The different configurations of the East Asian polar front jet and subtropical jet and the associated rainfall anomalies over eastern China in summer. J. Climate, 27, 8205-8220, https://doi.org/10.1175/ JCLI-D-14-00067.1.

_ _ _ _ _ - J. Wang, and X. Kuang, 2015: The impact of the East Asian subtropical jet and polar front jet on the frequency of spring persistent rainfall over southern China in 1997-2011. J. Climate, 28, 6054-6066, https://doi.org/10.1175/JCLI-D-1400641.1.

- - - Y.-C. Zhang, Y. Huang, and X.-Y. Kuang, 2016: Assessment of summer monsoon precipitation derived from five reanalysis datasets over East Asia. Quart. J. Roy. Meteor. Soc., 142, 108-119, https://doi.org/10.1002/qj.2634.

—, A. Dai, J. Zhu, Y. Zhang, and X. Kuang, 2017: Recent winter precipitation changes over eastern China in different warming periods and the associated East Asian jets and oceanic conditions. J. Climate, 30, 4443-4462, https://doi.org/10.1175/ JCLI-D-16-0517.1.

- - - B. Yang, P. Yan, J. Zhu, and Y. Zhang, 2019: Contributions of different combinations of the IPO and AMO to recent changes in winter East Asian jets. J. Climate, 32, 1607-1626, https://doi.org/10.1175/JCLI-D-18-0218.1.

Huang, R., and F. Sun, 1992: Impacts of the tropical western Pacific on the East Asian summer monsoon. J. Meteor. Soc. Japan, 70, 243-256, https://doi.org/10.2151/jmsj1965.70.1B_243.

Huang, X., and Coauthors, 2020: The recent decline revovery of Indian summer monsoon rainfall: Relative roles of external forcing and internal variability. J. Climate, 33, 5035-5060, https://doi.org/10.1175/JCLI-D-19-0833.1.

Joshi, M. K., and A. Rai, 2015: Combined interplay of the Atlantic multidecadal oscillation and the interdecadal Pacific oscillation on rainfall and its extremes over Indian subcontinent. Climate Dyn., 44, 3339-3359, https://doi.org/10.1007/s00382-014-2333-z.

_ cillation on Indian summer monsoon rainfall : An assessment from CMIP5 climate models. Climate Dyn., 48, 2375-2391, https://doi.org/10.1007/s00382-016-3210-8.

Kalnay, E., and Coauthors, 1996: The NCEP/NCAR 40-Year Reanalysis Project. Bull. Amer. Meteor. Soc., 77, 437-471, https://doi.org/10.1175/1520-0477(1996)077<0437:TNYRP> 2.0.CO;2.

Kug, J.-S., D.-H. Choi, F.-F. Jin, W.-T. Kwon, and H.-L. Ren, 2010: Role of synoptic eddy feedback on polar climate responses to the anthropogenic forcing. Geophys. Res. Lett., 37, L14704, https://doi.org/10.1029/2010GL043673.

Kwon, M., J.-G. Jhun, and K.-J. Ha, 2007: Decadal change in East Asian summer monsoon circulation in the mid-1990s Geophys. Res. Lett., 34, L21706, https://doi.org/10.1029/ 2007 GL031977.

Li, L., and Y. Zhang, 2014: Effects of different configurations of the East Asian subtropical and polar front jets on precipitation during the mei-yu season. J. Climate, 27, 6660-6672, https:// doi.org/10.1175/JCLI-D-14-00021.1.

Li, S., Y. Wang, and Y. Hao, 2009: A review of the researches on the Atlantic Multidecadal Oscillation (AMO) and its climate influence (in Chinese). Trans. Atmos. Sci., 32, 458-465.

Liao, Z., and Y. Zhang, 2013: Concurrent variation between the East Asian subtropical jet and polar front jet during persistent snowstorm period in 2008 winter over southern China. J. Geophys. Res. Atmos., 118, 6360-6373, https://doi.org/10.1002/JGRD.50558.
Lin, Z., and R. Lu, 2009: The ENSO's effect on eastern China rainfall in the following early summer. Adv. Atmos. Sci., 26, 333-342, https://doi.org/10.1007/s00376-009-0333-4.

Liu, Z., 2012: Dynamics of interdecadal climate variability: A historical perspective. J. Climate, 25, 1963-1995, https://doi.org/ 10.1175/2011JCLI3980.1.

Lu, R., 2005: Interannual variation of North China rainfall in rainy season and SSTs in the equatorial eastern Pacific. Chin. Sci. Bull., 50, 2069-2073, https://doi.org/10.1007/BF03322803.

, and Z. Lin, 2009: Role of subtropical precipitation anomalies in maintaining the summertime meridional teleconnection over the western North Pacific and East Asia. J. Climate, 22, 2058-2072, https://doi.org/10.1175/2008JCLI2444.1.

, H. Ye, and J.-G. Jhun, 2011: Weakening of interannual variability in the summer East Asian upper-tropospheric westerly jet since the mid-1990s. Adv. Atmos. Sci., 28, 1246-1258, https://doi.org/10.1007/s00376-011-0222-5.

_ Z Z. Lin, and Y. Zhang, 2013: Variability of the East Asian upper-tropospheric jet in summer and its impacts on the East Asian monsoon (in Chinese). Chin. J. Atmos. Sci., 37, 331-340.

Lunkeit, F., K. Fraedrich, and S. E. Bauer, 1998: Storm tracks in a warmer climate: Sensitivity studies with a simplified global circulation model. Climate Dyn., 14, 813-826, https://doi.org/ $10.1007 / \mathrm{s} 003820050257$.

Luo, X., and Y. Zhang, 2015: The linkage between upper-level jet streams over East Asia and East Asian winter monsoon variability. J. Climate, 28, 9013-9028, https://doi.org/10.1175/JCLID-15-0160.1.

Neale, R. B., and Coauthors, 2012: Description of the NCAR Community Atmosphere Model (CAM5.0). NCAR Tech. Note NCAR/TN+486+STR, 274 pp., https://www.cesm.ucar.edu/ models/cesm1.0/cam/docs/description/cam5_desc.pdf.

Power, S., T. Casey, C. Folland, A. Colman, and V. Mehta, 1999: Interdecadal modulation of the impact of ENSO on Australia. Climate Dyn., 15, 319-324, https://doi.org/10.1007/s003820050284.

Qian, C., J.-Y. Yu, and G. Chen, 2014: Decadal summer drought frequency in China: The increasing influence of the Atlantic Multi-decadal Oscillation. Environ. Res. Lett., 9, 124004, https://doi.org/10.1088/1748-9326/9/12/124004.

Qian, Y., Q. Wang, and D. Huang, 2007: Studies of floods and droughts in the Yangtze-Huaihe River basin (in Chinese). Chin. J. Atmos. Sci., 31, 1279-1289.

Qu, X., and G. Huang, 2012: Impacts of tropical Indian Ocean SST on the meridional displacement of East Asian jet in boreal summer. Int. J. Climatol., 32, 2073-2080, https://doi.org/ 10.1002/joc.2378

Ren, X., X. Yang, and C. Chu, 2010: Seasonal variations of the synoptic-scale transient eddy activity and polar front jet over East Asia. J. Climate, 23, 3222-3233, https://doi.org/10.1175/ 2009JCLI3225.1.

Sampe, T., and S.-P. Xie, 2010: Large-scale dynamics of the meiyubaiu rainband: Environmental forcing by the westerly jet. J. Climate, 23, 113-134, https://doi.org/10.1175/2009JCLI3128.1.

Seidel, D., Q. Fu, W. Randel, and T. Reichler, 2008: Widening of the tropical belt in a changing climate. Nat. Geosci., 1, 21-24, https://doi.org/10.1038/ngeo.2007.38.

Si, D., Y. Ding, and Y. Liu, 2009: Decadal northward shift of the Meiyu belt and the possible cause. Chin. Sci. Bull., 54, 47424748, https://doi.org/10.1007/S11434-009-0385-Y.

Sun, W., J. Li, R. Yu, and W. Yuan, 2015: Two major circulation structures leading to heavy summer rainfall over central north China. J. Geophys. Res. Atmos., 120, 4466-4482, https:// doi.org/10.1002/2014JD022853. 
Sutton, R. T., and B. Dong, 2012: Atlantic Ocean influence on a shift in European climate in the 1990s. Nat. Geosci., 5, 788792, https://doi.org/10.1038/ngeo1595.

Takaya, K., and H. Nakamura, 2001: A formulation of a phaseindependent wave-activity flux for stationary and migratory quasigeostrophic eddies on a zonally varying basic flow. J. Atmos. Sci., 58, 608-627, https://doi.org/10.1175/1520-0469(2001)058<0608: AFOAPI $>2.0 . \mathrm{CO} ; 2$.

Trenberth, K. E., and D. J. Shea, 2006: Atlantic hurricanes and natural variability in 2005. Geophys. Res. Lett., 33, L12704, https://doi.org/10.1029/2006GL026894.

Tsuyuki, T., and K. Kurihara, 1989: Impact of convective activity in the western tropical Pacific on the East Asian summer circulation. J. Meteor. Soc. Japan, 67, 231-247, https://doi.org/ 10.2151/jmsj1965.67.2_231.

Wang, B., R. Wu, and X. Fu, 2000: Pacific-East Asian teleconnection: How does ENSO affect East Asian climate? J. Climate, 13, 1517 1536, https://doi.org/10.1175/1520-0442(2000)013<1517: PEATHD $>2.0 . \mathrm{CO} ; 2$.

Xue, D., and Y. Zhang, 2017: Concurrent variations in the location and intensity of the Asian winter jet streams and the possible mechanism. Climate Dyn., 49, 37-52, https://doi.org/10.1007/ s00382-016-3325-y.

Yan, P., and D. Huang, 2017: The characterstics of summer persistent rainfall over Yangtze-Huaihe River valley and its relationship with the East Asian jet streams (in Chinese). J. Trop. Meteor., 33, 741749.

Yang, Q., Z. Ma, P. Wu, and N. P. Klingaman, and L. Zhang, 2019: Interdecadal seesaw of precipitation variability between North China and the Southwest United States. J. Climate, 32, 29512968, https://doi.org/10.1175/JCLI-D-18-0082.1.

Yim, B. Y., H. S. Min, and J.-S. Kug, 2015: Inter-model diversity in jet stream changes and its relation to Arctic climate in CMIP5. Climate Dyn., 47, 235-248, https://doi.org/10.1007/s00382-015-2833-5.

Zhang, R., A. Sumi, and M. Kimoto, 1996: Impact of El Niño on the East Asian monsoon: A diagnostic study of the ' $86 / 87$ and ' $91 /$ 92 events. J. Meteor. Soc. Japan, 74, 49-62, https://doi.org/ 10.2151/jmsj1965.74.1_49.
Zhang, Y., and D. Huang, 2011: Has the East Asian westerly jet experienced a poleward displacement in recent decades? Adv. Atmos. Sci., 28, 1259-1265, https://doi.org/10.1007/s00376-0119185-9.

— X. Xuang, W. Guo, and T. Zhou, 2006: Seasonal evolution of the upper-tropospheric westerly jet core over East Asia. Geophys. Res. Lett., 33, L11708, https://doi.org/10.1029/2006GL026377.

- D. Wang, and X. Ren, 2008: Seasonal variation of the meridional wind in the temperate jet stream and its relationship to the Asian monsoon. Acta Meteor. Sin., 22, 446-454.

— P. Yan, Z. Liao, D. Huang, and Y. Zhang, 2019: The winter concurrent meridional shift of the East Asian jet streams and the associated thermal conditions. J. Climate, 32, 2075-2088, https://doi.org/10.1175/JCLI-D-18-0085.1.

Zhang, Z., X. Sun, and X. Yang, 2018: Understanding the interdecadal variability of East Asian summer monsoon precipitation: Joint influence of three oceanic signals. J. Climate, 31, 5485-5506, https://doi.org/10.1175/JCLI-D-17-0657.1.

Zhu, J., D. Huang, Y. Zhang, A. Huang, X. Kuang, and Y. Huang, 2013: Decadal changes of Meiyu rainfall around 1991 and its relationship with two types of ENSO. J. Geophys. Res. Atmos., 118, 9766-9777, https://doi.org/10.1002/JGRD.50779.

$\longrightarrow, \ldots$, Y. Dai, and X. Chen, 2016a: Recent heterogeneous warming and the associated summer precipitation over eastern China. Theor. Appl. Climatol., 123, 619-627, https:// doi.org/10.1007/s00704-015-1380-7.

,$- \ldots$, and T. Yang, 2016b: Changes of Meiyu system in the future under A1B scenario simulated by MIROC_Hires model. Theor. Appl. Climatol., 123, 461-471, https://doi.org/ 10.1007/s00704-015-1371-8.

— D.-Q. Huang, P.-W. Yan, Y. Huang, and X.-Y. Kuang, 2017: Can reanalysis datasets describe the persistent temperature and precipitation extremes over China? Theor. Appl. Climatol., 130, 655-671, https://doi.org/10.1007/s00704-016-1912-9.

Zhu, Y., and X. Yang, 2003: Relationships between Pacific Decadal Oscillation (PDO) and climate variabilities in China (in Chinese). Acta Meteor. Sin., 61, 641-654. 